\title{
Do momentum and reversal strategies work in commodity futures? A comprehensive study
}

Article

Accepted Version

Zhang, H. and Urquhart, A. (2020) Do momentum and reversal strategies work in commodity futures? A comprehensive study. Review of Behavioural Finance, 12 (4). pp. 375-409. ISSN 1940-5979 doi: https://doi.org/10.1108/RBF-05-2019-0067 Available at https://centaur.reading.ac.uk/87467/

It is advisable to refer to the publisher's version if you intend to cite from the work. See Guidance on citing.

To link to this article DOI: http://dx.doi.org/10.1108/RBF-05-2019-0067

Publisher: Emerald

All outputs in CentAUR are protected by Intellectual Property Rights law, including copyright law. Copyright and IPR is retained by the creators or other copyright holders. Terms and conditions for use of this material are defined in the End User Agreement.

$\underline{\text { www.reading.ac.uk/centaur }}$ 
Central Archive at the University of Reading

Reading's research outputs online 


\title{
Do momentum and reversal strategies work in commodity futures? A comprehensive study
}

\begin{abstract}
This paper investigates the performance of three different investment trading strategies in 29 commodity futures from January 1979 to October 2017. We find there is no significant reversal profit across 189 formation-holding windows for all the three strategies. However, there are statistical and economically significant momentum profits, and the profitability increases with the rising of formationholding periods. Momentum returns are quite sensitive to market conditions but the crash of momentum returns are partly predictable. Return seasonality, risk and herding also provide partial explanation of the momentum profits.
\end{abstract}

Keywords: Commodity futures, Momentum, Reversal, Formation-holding windows, Herding.

JEL classification: G11, G12, G13, G14. 


\section{Introduction}

Motivated by the debate on the patterns and sources of commodity futures returns, this paper investigates the performance of three investment trading strategies, namely, the momentum strategy of Jegadeesh and Titman $(1993)^{1}$ (henceforth, JT), the 52-week high momentum strategy of George and Hwang $(2004)^{2}$ (henceforth, GH) and the pairs trading strategy of Gatev et al. (2006) ${ }^{3}$ (henceforth, GGR) in the commodity futures market.

In the literature, Wang and $\mathrm{Yu}$ (2004) find that there is strong evidence of weekly return reversals in 24 US futures by using the strategies of selling the past best performers and buying the past worst performers. In contrast, Miffre and Rallis (2007) and Bianchi et al. (2015) find the reversal strategies are consistently unprofitable but a large number of the JT momentum strategies of buying the past best performers and selling the past worst performers are profitable. Narayan et al. (2015) find that momentum-based trading strategies can generate statistically significant profits on 19 commodity futures, although the profitability are somewhat sensitive to the short-selling, data frequency and subsample. Some evidence (Lee and Swaminathan, 2000; Fuertes et al., 2010; de Groot et al., 2014; Bianchi et al., 2015) also shows the double-sort momentum strategy (combining momentum with another factor, such as trading volume, term-structure and long-term return reversal) outperforms the single-sort strategy. Fuertes et al. (2015) find that the triple-sort momentum strategy (combination of JT momentum, term-structure, and idiosyncratic volatility) dominates the double-sort and single-sort strategies, and this outperform cannot be explained by overreaction, liquidity risk, transaction costs, or

\footnotetext{
${ }^{1}$ Jegadeesh and Titman (1993) find a momentum in short-term stock returns; a strategy that buying the past best performers and selling the past worst performers (the "momentum" strategy) often outperforms the market. In contrast, De Bondt and Thaler (1985) find a reversal in long-term stock returns; buying the past worst performers and selling the past best performers (the "contrarian" strategy) may also be profitable. Some researchers constrain the term "momentum" ("contrarian") to strategies over short-term horizon of 3 to 12 months (long-term horizons of 3 to 5 years) based on the typical empirical findings (Conrad and Kaul, 1998). For the sake of brevity and consistency, we use the term "JT momentum" ("reversal") to describe all the trading strategies that involve buying (selling) the past winners and selling (buying) the past losers regardless of the formation-holding horizon. Some literature argue that the reversal effect can be explained by a Fama-French 3-factor model (Fama and French, 1996), market microstructure effects (e.g., bid-ask spread bias and inventory effects) (Conrad and Kaul, 1998), liquidity (Cox and Peterson, 1994) and herding (Park and Sabourian, 2011). Others argue that momentum effect is largely associated with firm size (Hong et al., 2000) and trading volume (Connolly and Stivers, 2003). Other explanations of the profits from momentum and reversal strategies have been argued to be due to price under/overreaction (Barberis et al., 1998). Hong and Stein (1999) model a market consisting of 2 groups of bounded rational investors, namely, the "newswatchers" and "momentum traders". The market firstly underreacts to firm-specific news given newswatchers may receive information with a delay, causing the profitability of momentum strategies. The initial underreaction is generally followed by overreaction, since momentum traders make profit by chasing trend, which may drive prices overshoot their long-term equilibrium, and eventually causing the reversal in long-term returns. Hence, profitable momentum and reversal strategies could coexists but for different formation-holding windows (Barberis et al., 1998; Conrad and Kaul, 1998; Hong and Stein, 1999).

${ }^{2}$ George and Hwang (2004) find a 52-week high momentum strategy that buying equities with a high current price to past 52-week high price ratio beats those with a low ratio. The profitability of GH strategy could be explained by the anchoring bias where investors are reluctant to bid the price of the asset higher even if the fundamentals of information supports it. When information eventually prevails, asset prices move to a new equilibrium hence causing return momentum and momentum effect (Liu et al., 2011; Bhootra and Hur, 2013). For the sake of brevity, we use the term "GH momentum" to describe all the trading strategies that involve buying the assets with a high current price to past $J$-month high price ratio and selling those with a low ratio regardless of the formation-holding horizon.

${ }^{3}$ Gatev et al. (2006) find a pairs trading strategy, based on the $12 \times 6$ formation-holding window, is profitable in the US equity market. The rationale behind GGR is to profit from revision forces that eliminate short-term price deviations in favour of long-term historical pricing relationships. Essentially, investors find two equities whose prices move together over a specified historical period and when the pair prices deviate wide enough, the investor should buy the declining price equity and sell the increasing price equity. We use the term "GGR" to describe all the trading strategies which are in the spirit of Gatev et al. (2006) regardless of the formation-holding horizon.
} 
the financialization of commodity futures markets. Bianchi et al. (2016) find the 52-week high momentum strategy of GH is superior to JT momentum while they also show that momentum and reversal can coexist in commodity futures, as suggested by the behavioural models of literature (Barberis et al., 1998; Hong and Stein, 1999). Unlike JT and GH, Bianchi et al. (2009) is one of the very few literature that studies and confirms the profitability of GGR pairs trading strategy in commodity futures market (Krauss, 2017). Lubnau and Todorova (2015) form portfolios based on the mean-reverting calendar spread, which are established with dynamic hedge ratios and find that most combinations are significantly profitable, with the best combinations generating Sharpe ratios greater than 2.

However, the literature is far from complete. For example, none of the aforementioned literature examines the relationship between formation-holding window and the profitability of GGR. Although some literature (Jegadeesh and Titman, 2001; Shen et al., 2007; Bianchi et al., 2015,2016) investigates the post-holding-period return of JT momentum by studying the holding period returns of up to 60 months after portfolio formation, they do not show whether these post-holding-period returns are statistically significant across the formation-holding windows. Without testing the statistical significance, the pattern of post-holding-period returns might be spurious because the inference is based on a sample rather than the entire population. Miffre and Rallis (2007) study the average monthly JT momentum returns across 32 low-formation-low-holding windows with statistical significance tests, however, this is insufficient to draw solid inference since the momentum returns may reverse under high-formation-high-holding windows. It also remains unclear how different strategies perform under different market conditions. Hence, the competing results in literature may simply because they applied strategies under different formation-holding windows and/or different market conditions. Apart from Bianchi et al. (2009), none of the literature tests the profitability of GGR strategy in commodity futures to the best of our knowledge. Although the crash of momentum strategies are partly predictable (Barroso and Santa-Clara, 2015; Daniel and Moskowitz, 2016), it still remains unclear whether different strategies crash simultaneously. If strategies do not crash simultaneously, investors may switch trading strategies accordingly in order to optimize their risk-return trade-off. Moreover, there is a lack of evidence whether the momentum/reversal returns are associated with herding in commodity futures market. When herding occurs, correlation among asset returns increase significantly, risk reduction via diversification may become much harder (Chiang and Zheng, 2010; Economou et al., 2011; Chen et al., 2018), which may also be an amplification mechanism for momentum/reversal returns.

On the purpose of filling the aforementioned literature gaps, this paper assesses the return patterns in 29 commodity futures for the three methods discussed above (JT, GH, and GGR) for the period from January 1979 to October 2017 where our results have four main findings. First, in contrast to the GGR pairs trading literature (Gatev et al., 2006; Bianchi et al., 2009; Do and Faff, 2012; Rad et al., 2016; Zhang and Urquhart, 2019), we find the conventional GGR pairs trading strategy in the commodity futures market are consistently unprofitable across 189 formation-holding windows but the inverse of GGR pairs trading strategies are profitable for a large number of formation-holding windows. Opposite to the conventional GGR pairs trading strategy, the inverse of GGR strategy buying the increasing-price commodity futures and selling the declining-price commodity futures when the trading signal appears. Specially, for low (high) formation periods, especially when the formation period less than 12 (higher than 24) months, the average monthly returns of conventional GGR strategies are likely to be significantly negative when the holding period ranges from 12 to 36 months (from 1 to 60 months). Given that "pairs trading is in essence a contrarian investment strategy" (Gatev et al., 2006, p. 807) and momentum effect is opposite to reversal effect by construction (Chen et al., 2018), the inverse of GGR pairs trading strategy is in essence a quasi-momentum strategy. Hence, a statistically significant negative (positive) return for the conventional GGR pairs trading strategy means significant momentum (reversal) return. JT and GH also suggest there is no statistically significant reversal but momentum profits in the commodity futures market. Consistent with Bianchi et al. (2015) and Bianchi et al. (2016), there is a clear reversal pattern of return for the JT and GH momentum strategies from 15 to 36 months 
after portfolio formation, in particular when the formation period is longer than 6 months. However, the reversed momentum profits are statistically significant only when the holding period is longer than 30 months associated with formation period longer than 36 months thereby complement Miffre and Rallis (2007), Bianchi et al. (2015) and Bianchi et al. (2016). A number of risk-adjusted performance measures suggest the inverse of GGR pairs trading strategy is more likely to outperform JT and GH prior to 1998, thereafter the superiority declines sharply. Furthermore, the performances of the three strategies are quite sensitive to the formation-holding windows since 1998.

Second, the performances of momentum returns are partly predictable. The Markov regime switching model suggests the duration for exuberance period of momentum returns is longer and more persistent than the crisis period, apart from the fully invested weighting scheme based inverse of GGR. The nontemporal threshold regression indicates that the profitability of the best inverse GGR pairs trading and the GH momentum strategies will be deteriorated when global funding liquidity beyond certain levels. The best performing JT momentum strategy may turn unprofitable when market sentiment is above certain level. The existence of multiple market regimes confirms the non-linearity relationships between momentum returns and risk factors, which may not be capture by the linear regressions in literature. Given that the crash of these strategies are partly predictable and not simultaneously, rationale investors could switch between these alternative trading strategies when market conditions change. Bianchi et al. (2015) and Bianchi et al. (2016) use quantile regressions to study the performances of momentum returns under extreme market regimes. However, the selection of quantiles is arbitrary by using a value of $20 \%$ or $80 \%$ as the cut-off point to identify the extreme market conditions. In practice, investors may differ in their opinions as to what constitutes an extreme regime.

Third, the profitability of the inverse GGR pairs trading strategy cannot be explained by JT or GH. Similarly, the profitability of JT or GH cannot be explained by the inverse of GGR pairs trading returns. The profitability of fully invested weighting scheme based inverse GGR (JT) can be largely explained by committed capital weighting scheme based inverse GGR $(\mathrm{GH})$. However, the profitability of committed capital weighting scheme based inverse GGR (GH) strategy cannot be attributed to the profitability of fully invested weighting scheme based inverse GGR (JT). Stock market momentum cannot explain the momentum returns in commodity futures. The momentum returns consistently report December effect rather than January effect, which contrasts to the literature in equity markets (Jegadeesh and Titman, 1993; George and Hwang, 2004).

Last but not least, we show that the aggregate commodity futures market is susceptible to herding behaviour on a daily basis but not on a monthly basis, especially when the market uncertainty is higher or the daily S\&P 500 return is lower than certain levels. The winners of JT are associated with herding when the monthly S\&P 500 return is higher than $3.66 \%$ or the monthly GSCI World return is higher than $2.37 \%$. There is no herding for the rest of strategies. Overall, the inverse of GGR strategies are quite different from JT and GH momentum by nature, and hence provide alternative trading strategies to investors.

Although this paper is closely related to Bianchi et al. (2009), Bianchi et al. (2015) and Bianchi et al. (2016), we modify the empirical methodologies for each of the following major ways in which the 4 papers differ: (1) Bianchi et al. (2015) and Bianchi et al. (2016) only study the post-holding-period return of JT momentum strategy using cumulative monthly return and do not discuss whether the observed post-holding-period returns are statistically significant, whereas we use the average monthly returns for GGR pairs trading, GH 52-week high momentum and JT momentum across different formation-holding windows, and report their corresponding statistical significance, which could add robustness to inferences; (2) Bianchi et al. (2009) studied the profitability of GGR pairs trading strategy by using 1 formation-holding window, Bianchi et al. (2015) compare the profitability of JT momentum to double-sort momentum with a maximum of 40 formation-holding windows, Bianchi et al. (2016) compare JT momentum, 52-week high and 52-week low of GH momentum strategies under 1 
formation-holding window, whereas we compare the GGR pairs trading and GH 52-week high momentum to JT momentum across 189 formation-holding windows, which could add completeness to literature; (3) Bianchi et al. (2015) and Bianchi et al. (2016) study the factor loadings of the momentum returns using linear regression or quantile regression, whereas we use the multiple non-temporal threshold regression and Markov regime switching regression, which could capture non-linearity of momentum returns endogenously; (4) Bianchi et al. (2015) and Bianchi et al. (2016) study the seasonality using cumulative return of momentum portfolios by excluding sub-sector commodity futures, whereas we study the calendar anomalies such as January effect by estimating GARCH models on time-series returns. Additionally, we empirically investigate the source of calendar anomalies. Appreciating the impact of these methodological differences is important to our knowledge of commodity futures. Moreover, each of these differences suggests a significant change in the implementation of trading strategies in practice.

This paper makes three main contributions to the literature. Firstly, we are the first to compare the performances of the pairs trading of Gatev et al. (2006), the conventional momentum of Jegadeesh and Titman (1993), and the 52-high momentum of George and Hwang (2004) under 189 formation-holding windows. The formation-holding window including any combination of 9 formation periods from 1 to 60 months and 21 holding periods from 1 to 60 months. Secondly, we extend the momentum literature (Barroso and Santa-Clara, 2015; Daniel and Moskowitz, 2016) by testing whether the best performed momentum strategies crash under certain market conditions through the Markov regime switching model and the non-temporal threshold regressions. Both models allow for regime-switching and identify market conditions endogenously, the main difference is that the Markov model assumes that the underlying regime process that gives increase to the nonlinear dynamics is unobservable, whereas the threshold model allows the nonlinear effect to be driven by observable variables but the number of thresholds and the threshold values are not known a prior. The two models thus complement each other and capture the non-linearity properties of momentum returns. Thirdly, we are the first to investigate the association between herding behaviour and momentum returns in the commodity futures market.

The rest of the paper is organized as follows. Section 2 introduces the data. Section 3 presents the empirical methodology. Section 4 provides a detailed comparison of the performances of the 3 trading strategies, followed by discussion on momentum has its moments, diversification benefits, calendar anomalies and herding behaviour. The last section concludes.

\section{Data}

Our data sample consists of 29 individual commodity futures excess return indices published by the Standard and Poor's (S\&P) ${ }^{4}$ from 3 broad sectors, namely, 6 energy commodities (Brent crude, Gas oil, Heating oil, Natural gas, RBOB gas and WTI crude), 10 metal commodities (Aluminum, Copper, Gold, Lead, Nickel, Palladium, Platinum, Silver, Tin and Zinc) and 13 Agriculture \& Live Stock commodities (Cocoa, Coffee, Corn, Cotton, Feeder cattle, Lean hogs, Live cattle, Soybean, Soybean meal, Soybean oil, Sugar, Chicago wheat and Kansas wheat). Given that there are only 5 commodity futures are available at the inception date ( $31^{\text {st }}$ December 1969), we adjust the start date to $1^{\text {st }}$ January 1979 to ensure enough commodity futures to create realistic trading strategies. The daily commodity futures

\footnotetext{
${ }^{4}$ Compared to the self-compiled commodity futures price series, the S\&P GSCI indices have three main advantages. First, the S\&P GSCI data are widely used for benchmarking in the commodities market, and the individual indices reflect the real returns available to investors. Second, the calculation of the S\&P GSCI indices are overseen by committees and advisory panels, thus it is sensible to believe quality advantages over the selfcompiled price series. Third, the individual futures contracts are quite difficult to manage as many commodities are traded across different exchanges (Bianchi et al., 2015). de Groot et al. (2014) employ total return indices of 24 S\&P GSCI constituents from January 1990 to September 2011. Bianchi et al. (2015) use 27 S\&P GSCI excess return indices from January 1977 to December 2011. Bianchi et al. (2016) employ 30 S\&P GSCI excess return indices from January 1977 to July 2013.
} 
prices, proxied by the futures excess returns indices, are collected from Datastream over the period from $1^{\text {st }}$ January 1979 to $31^{\text {st }}$ October 2017 , all the non-trading days are excluded. The excess return index captures the theoretical return from investing in nearby S\&P GSCI futures and rolling them forward on the $5^{\text {th }}$ to $9^{\text {th }}$ business days of each month. Following the literature (Bianchi et al., 2015,2016), we assume the combined long-short strategy is approximately $50 \%$ collateralized, therefore, the uninvested capital may be used to facilitate potential margin calls trigged before the end of each holding period. The long-short strategies should generate collateral returns in excess of any margin call in addition to the futures returns. Given that the excess return index excludes the risk-free interest earned from the deposit account, Equation (1) effectively calculates the simple excess returns $\left(R_{i, t}\right)$ for commodity futures $i$. All the commodity futures are denominated by the US dollar.

$$
R_{i, t}=\frac{P_{i, t}-P_{i, t-1}}{P_{i, t-1}} \times 100
$$

Where, $P_{i, t}$ is the price (proxied by the futures excess returns indices) for commodity futures $i$ at time $t$. Table 1 presents the ticker symbol, exchange information, start dates of each commodity futures as well as the descriptive statistics for each commodity futures. The vast majority of futures have a positive mean return with palladium having the largest positive mean return while natural gas has the largest negative return. Natural gas also has the highest standard deviation while feeder cattle has the smallest standard deviation. Most commodities have positive skewness while all have excess kurtosis and therefore a leptokurtic distribution.

[Table 1 about here]

\section{Methodology}

\subsection{Trading strategies}

We compare the profitability of 3 trading strategies, namely, the pairs trading strategy of Gatev et al. (2006), the conventional momentum strategy of Jegadeesh and Titman (1993) and the 52-high momentum strategy of George and Hwang (2004). All the three strategies involve preceding in a $J$ month formation period and a $K$-month trading period.

\subsubsection{The pairs trading strategy of Gatev et al. (2006)}

At the beginning of each formation period, the price for each commodity futures is normalized such that:

$$
P_{i, t ; t+1 ; t+2 ; \ldots ; T-1}^{*}=\frac{P_{i, t ; t+1 ; t+2 ; \ldots ; t+T_{F}-1}}{P_{i, t}}
$$

Where, $P_{i, t}^{*}$ is the normalized daily price index of commodity futures $i$ on day $t . P_{i, t+1}^{*}$ is the normalized daily price of commodity futures $i$ on day $t+1$. $P_{i, t}$ is the daily price series of commodity futures $i$ on day $t . T_{F}-1$ is the number of trading days in the formation period. Pairs are identified for trading by matching each commodity futures $i$ with a second commodity futures $j$ that has the smallest Sum of Squared Deviation $\left(S S D_{i, j}\right)$ between the two normalized price series over the $J$-month formation period.

$$
S S D_{i, j}=\sum_{t=1}^{T_{F}}\left(P_{i, t}^{*}-P_{j, t}^{*}\right)^{2}
$$


Top $N$ pairs, ranked by smallest Sum of Squared Deviations $\left(S S D_{i, j}\right)$, are selected at the end of each $J$ month formation period and are traded over the following $K$-month trading period. We use the top 5 pairs for trading since we have only 29 commodity futures.

The trading period starts on the first trading day following the end of the $J$-month formation period. During the trading period, the pair trade is opened when the normalized prices diverge by more than 2 historical standard deviations of the price difference during the formation period. The conventional (inverse) pair trade is opened by purchasing (selling) 1 US Dollar in the commodity futures with lower normalized price, and selling (longing) 1 US Dollar in the commodity futures with higher normalized price. The pair trade is closed when the normalized price series converge, or on the last day in the $K$ month trading period whether or not price convergence happened. We apply the GGR strategy at the end of the day when the trading signal appears. ${ }^{5}$

To calculate the return for a pair of commodity futures throughout the trading period, we accumulate weighted daily returns from the long and short positions. The daily percentage excess returns for a pair $\left(R_{p, t}\right)$ is calculated as Equation (4). ${ }^{6}$

$$
R_{p, t}=w_{L, t} R_{L, t}-w_{S, t} R_{S, t}
$$

Where, $R_{L, t}$ and $R_{S, t}$ are the daily simple excess returns for the long position and short position. The weights for both commodity futures $\left(w_{L, t}\right.$ and $\left.w_{S, t}\right)$ are set to start from 1 after which they change according to the moves in the value of the commodity futures (Broussard and Vaihekoski, 2012).

$$
w_{i, t}=w_{i, t-1}\left(1+R_{i, t-1}\right)
$$

The GGR strategy is designed to begin without any investment, but as the weights $\left(w_{L, t}\right.$ and $\left.w_{S, t}\right)$ change in Equation (4), the position has either a positive or negative net value over the trading period. ${ }^{7}$

Based on the excess return series for each pair, we can generate the excess return for a portfolio of the pairs at time $t\left(R_{P, t}\right)$. We employ two alternative equal-weighted schemes. The first one is named Committed Capital scheme (henceforth, $\mathrm{CC}$ ), which basically commits equal amounts of investment to each one of the $N$ pairs. If the pair is not opened, or closed during the trading period, the investment is still committed to the pair. We assume 0 return for non-open pairs. The second one is named Fully Invested scheme (henceforth, FI), which assumes investment is always divided between the pairs that are open. For the FI scheme, the investment from a closed pair is invested in the other pairs that are open. If the pair is re-opened, the investment is invested back by moving the capital between the pairs according to their relative weights. Hence, the equal-weighted portfolio return is calculated as the sum of pairs returns divided either by the number of pairs $(N=5)$ or the number of pairs that are open an any given date for the $\mathrm{CC}$ and FI, respectively. By nature, $\mathrm{CC}$ is more conservative than FI. The daily portfolio excess returns of pairs are then compounded to generate a monthly time-series of excess returns.

\footnotetext{
${ }^{5}$ It means that every day closing prices are used to determine whether a pair should be opened. If a signal is received, one is assumed to be able to buy the very second the commodity futures for the same closing prices (that was used to determine the signal). A bit theoretical, but doable even in practice given the high liquidity of commodity futures (Fuertes et al., 2010; Bianchi et al., 2015,2016).

${ }^{6}$ As discussed in literature (Gatev et al., 2006; Broussard and Vaihekoski, 2012), $R_{p, t}$ in Equation (4) can be interpreted as the excess return since the risk-free rate is cancelled if one calculates the excess return or raw return on both legs of the pair.

${ }^{7}$ Technically, it is easy to force the weights to remain the same implying a net 0 position, however, in practice it means daily rebalancing the positions and would leading to high transaction costs.
} 


\subsubsection{The momentum strategy of Jegadeesh and Titman (1993)}

At the end of each month, all commodity futures are ranked in ascending order based on their cumulative returns over the past $J$-month. The end-of-the-month price is used to calculate the cumulative return (Jegadeesh and Titman, 1993; Fuertes et al., 2010; Bianchi et al., 2016). Accordingly, 2 equal-weighted portfolios are constructed: commodity futures ranked in the top $30 \%$ are assigned to the winner portfolio, and the bottom $30 \%$ are assigned to the loser portfolio. ${ }^{8}$

\subsubsection{The 52-week high momentum strategy of George and Hwang (2004)}

At the end of each month, all commodity futures are ranked in ascending order based on their nearness to the past $J$-month high ratio. The nearness ratio is defined as $\left(P_{i, t-1} / H i g h_{i, t-1}\right)$, where $P_{i, t}$ is the price of commodity futures $i$ at the end of month $t$ and $H i g h_{i, t}$ is the highest price of commodity futures $i$ during the past $J$-month. If the formation month end price is the past $J$-month high price, then the nearness ratio has the maximum value of 1 . Consistent with the JT strategy, 2 equal-weighted portfolios are constructed: commodity futures ranked in the top 30\% are assigned to the winner portfolio, and the bottom 30\% are assigned to the loser portfolio (George and Hwang, 2004; Bhootra and Hur, 2013; Bianchi et al., 2016).

For the JT and GH strategies, a momentum portfolio can be constructed by longing the winner portfolio and shorting the losing portfolio, while holding the position for the following $K$-month. Given that the "pairs trading is in essence a contrarian investment strategy" (Gatev et al., 2006, p. 807) and momentum effect is opposite to reversal effect (Chen et al., 2018), the inverse of GGR pairs trading strategy is in essence a momentum-like strategy. A statistically significant positive (negative) return for the momentum-type strategy means loss (profit) for reversal-type strategy.

There is no daily or monthly gap skip between formation and holding periods since trading strategies in the commodities market do not suffer from the short-term reversal and bid-ask bounce effects (Bianchi et al., 2015,2016), skipping the first month yields inferior results (Shen et al., 2007; Fuertes et al., 2010). By repeating the $J \times K$ implementation cycle forward 1-month each time, there are $K$ overlapping trading periods of excess returns, which are averaged to yield monthly excess return series for each strategy (Fuertes et al., 2010). ${ }^{9}$

\subsection{Test of herding}

The literature (Chiang and Zheng, 2010; Chen et al., 2018) defines herding as a scenario where investors mimic the trading activities of others, especially successful investors, rather than depending on their own due diligence research. Individual commodity futures differ in their sensitivity to the market return, and rational asset pricing models anticipate a linear relationship between the cross-section dispersion of commodity futures returns and the market return. When herding occurs, the cross-sectional dispersion of returns increase or decrease less than proportionally with the market return, given investors are drawn to the consensus of the market (Chen et al., 2018). Chiang and Zheng (2010) propose a herding-detection model as shown in Equation (6).

\footnotetext{
${ }^{8}$ Following the popular practice in literature, we use $30 \%$ breakpoints for the JT and the GH strategies but 5 pairs (up to 10) of commodity futures for the GGR strategies. As a robustness check, we also tried 10 pairs of commodity futures for the GGR strategies, the results are quite similar, the results are available upon request. Gatev et al. (2006) and Bowen and Hutchinson (2016) also find that the profitability of GGR strategy is not very sensitive to Top 5 or Top 20 pairs.

${ }^{9}$ Broussard and Vaihekoski (2012) rolls the $12 \times 6$ implementation cycle forward every 6-month and the pairs are formed using data either from January to December within a calendar year, or from July to June the following year. Bianchi et al. (2016) limit the holding period to 1 month, so all portfolios are non-overlapping.
} 


$$
\operatorname{CSAD}_{P, t}=\gamma_{0}+\gamma_{1} R_{m, t}+\gamma_{2}\left|R_{m, t}\right|+\gamma_{3} R_{m, t}^{2}+\varepsilon_{t}
$$

Where, $\operatorname{CSAD}_{P, t}$ is the cross-sectional absolute dispersion for portfolio $P$ at time $t$.

$$
\operatorname{CSAD}_{P, t}=\frac{1}{M} \sum_{i=1}^{M}\left|R_{i, t}-R_{m, t}\right|
$$

Where, $M$ is the number of commodity futures included in the portfolio, $R_{m, t}$ is the cross-sectional average of commodity futures excess returns in the portfolio at time $t$. A statistically significant negative $\gamma_{3}$ in Equation (6) suggests the dispersion of returns raises at a decreasing rate with the market return, which signals the herding behaviour.

In order to shed light on whether herding behaviour changes under different market conditions, we extend the herding-detection model of Chiang and Zheng (2010) by using the multiple non-temporal thresholds regression instead of using the Ordinary Least Square or Quantile regressions. The multiple non-temporal thresholds regression proposed by Gonzalo and Pitarakis (2002) extends the original single non-temporal threshold regression of Hansen (2000) by applying the multiple structural change analysis of Bai and Perron (1998). The non-temporal threshold regression ranks the time-series data of threshold variable in a non-temporal fashion, which endogenously identify the thresholds of market condition (Hansen, 2000,2011) and captures the non-linearity of market conditions. The extended herding-detection model is shown as Equation (8).

$$
\begin{array}{cl}
\operatorname{CSAD}_{P, t}=\gamma_{0,1}+\gamma_{1,1} R_{m, t}+\gamma_{2,1}\left|R_{m, t}\right|+\gamma_{3,1} R_{m, t}^{2}+\varepsilon_{1, t} & \text { if } X_{t} \leq x_{1} \\
\vdots & \\
\operatorname{CSAD}_{P, t}=\gamma_{0, s}+\gamma_{1, s} R_{m, t}+\gamma_{2, s}\left|R_{m, t}\right|+\gamma_{3, S} R_{m, t}^{2}+\varepsilon_{s, t} & \text { if } x_{s-1}<X_{t} \leq x_{s} \\
\vdots & \\
\operatorname{CSAD}_{P, t}=\gamma_{0, S+1}+\gamma_{1, S+1} R_{m, t}+\gamma_{2, S+1}\left|R_{m, t}\right|+\gamma_{3, S+1} R_{m, t}^{2}+\varepsilon_{S+1, t} & \text { if } x_{S}<X_{t}
\end{array}
$$

Where, $X_{t}$ is the threshold variable used to measure the market conditions. $S$ is the number of thresholds present in the data. The procedure begins with the null hypothesis of 0 threshold against the alternative of 1 threshold, if it rejects, proceeds to 2 thresholds and so on. We test up to 3 thresholds (4 regimes). The optimal number of thresholds is determined by minimizing the Bayesian Information Criterion (BIC). Gonzalo and Pitarakis (2002) find that the BIC displays the best performance of identifying the number of thresholds among a number of model selection criteria. The threshold values exclude the first and the last $10 \%$ of the ordered sample. A significantly negative $\gamma_{3, S+1}$ in Equation (8) suggests the presence of herding behaviour when the market condition beyond a certain level.

\section{Results}

\subsection{Formation-holding window and profitability}

Figure 1 displays the average monthly excess returns and the corresponding $p$-values of different trading strategies over the full sample from January 1979 to October 2017 under 189 formation-holding windows ( 9 formation periods $J=1,3,6,9,12,24,36,48,60$ combined with 21 holding periods $K=$ $1,3,6,9,12,15,18,21,24,27,30,33,36,39,42,45,48,51,54,57,60)$.

[Figure 1 about here]

Panels A and B report the conventional pairs trading strategy of Gatev et al. (2006) based on the equalweighed Committed Capital scheme (CC) and Fully Invested scheme (FI), respectively. The findings in Panels A and B contrast to the GGR pairs trading literature either in equity market (Gatev et al., 2006; Do and Faff, 2010; Broussard and Vaihekoski, 2012; Jacobs and Weber, 2015; Bowen and Hutchinson, 
2016; Rad et al., 2016; Liu et al., 2017; Zhang and Urquhart, 2019) or in commodity futures market (Bianchi et al., 2009) because we find the conventional GGR strategies consistently do not generate significant positive average monthly return. Given that "pairs trading is in essence a contrarian investment strategy" (Gatev et al., 2006, p. 807) and momentum strategy is the opposite of reversal strategy (Bianchi et al., 2015; Chen et al., 2018), the statistically and economically loss of GGR pairs trading in Panels A and B suggests the inverse of GGR strategies are profitable and there are momentum-like effect in the commodity futures market, especially for higher formation period $(J=24$, $36,48,60)$ rather than lower formation periods $(J=1,3,6,9,12)$.

Panels C and D display the average monthly momentum returns of Jegadeesh and Titman (1993) (JT) and George and Hwang (2004) (GH), respectively. Consistent with Miffre and Rallis (2007), Bianchi et al. (2015) and Bianchi et al. (2016) but contrast to Wang and Yu (2004), Panels C and D suggest that there are statistically and economically significant profits for the JT and GH momentum strategies. This is shown by the fact that there are a large number of significantly positive average monthly returns but none of the returns are statistically negative. We also find the magnitudes of JT momentum profits display an upward reversal pattern, especially when the holding period is between 18 and 36 months. However, we find the reversed momentum profits are statistically significant only when the holding period is longer than 30 months associated with formation period longer than 36 months. Furthermore, the JT and GH momentum are consistently unprofitable with medium holding period in commodity futures market. The findings in Panels C and D contrast to the momentum/reversal literature in the equity market. For instance, Conrad and Kaul (1998) find that momentum and reversal strategies are equally successful, albeit for different investment horizons, by using the NYSE/AMEX equities from 1926 to 1989. Novy-Marx (2012) find that momentum strategy based on medium formation window is more profitable than low formation window.

\subsection{Since none of the conventional GGR strategies are profitable, all the subsequent analysis for pairs trading are based on the inverse of GGR pairs trading, buying the declining price commodity futures and selling the increasing price commodity futures.Risk-adjusted performances}

Table 2 presents a summary of the best ${ }^{10}$, worst and average performance of CC, FI, JT and GH strategies across the 189 formation-holding windows over the full sample. Table 2 suggests the best and average performance of each strategy are positive and substantially outperform the S\&P GSCI in terms of Sharpe ratio, Sortino ratio, Information ratio and Jensen's alpha. While the Upside potential ratio, Calmar ratio and Excess return on $95 \%$ VaR report opposite findings, implying the momentum strategies may crash during extreme market conditions. From another perspective, the choice of performance measure matters for the investment evaluation of momentum returns. Moreover, the performances of the best under each strategy $\left(C C_{J=48, K=15}, F I_{J=60, K=1}, J T_{J=3, K=1}, G H_{J=12, K=1}\right)$ are significantly different from each other, as the GRS statistic of Gibbons et al. (1989) rejects the null hypothesis of equality of Jensen's alphas across the 4 momentum excess returns.

\section{[Table 2 about here]}

Complementing Table 2, Figure 2 box plots ${ }^{11}$ the performances of each trading strategy across the 189 formation-holding windows in 3 samples, namely, the full-sample 01/1979-10/2017, 01/1979-12/1997 and 01/1998-10/2017. Figure 2 indicates that the GH outperforms the rest strategies in terms of magnitude of average monthly return in the full sample. However, the inverse of GGR pairs trading strategies, both CC and FI, are more likely to generate statistically significant profits than JT and GH.

\footnotetext{
${ }^{10}$ The best is based on highest average monthly return. For FI, JT and GH, the best also reports the highest Sharp ratio.

${ }^{11}$ Figure A1 shows the interpretation of the box plot.
} 
Moreover, the Sharpe ratio, Sortino ratio, Calmar ratio, and $t$-statistics of Jansen's alpha ${ }^{12}$ suggest the inverse of GGR tend to generate superior risk-adjusted performances than JT and GH, although the superiority declines sharply since 1998. The Excess return on 95\% VaR suggests the JT has superior performance prior to 1998. The investment returns are quite sensitive to the formation-holding window since 1998, as shown by the larger dispersion of performances.

For the sake of brevity, the rest of paper only presents the results for best performing strategies in each category: GGR, JT and GH, given that the main conclusions are qualitatively unchanged but investors are generally more interested in the performance of profitable strategies. All the empirical results are available upon request.

[Figure 2 about here]

\subsection{The moment of investment returns}

In order to investigate whether the profitable trading strategies reflect compensation for bearing systematic risk under different market conditions (Ang and Timmermann, 2012), Table 3 presents the Markov regime switching ${ }^{13}$ regression results for the best of each trading strategy over the full sample through the 6-factor model of Fuertes et al. (2010) and a single-factor model. The 6-factor model including returns on the S\&P 500, S\&P GSCI, US Government Bond, US dollar effective exchange rate index, US unexpected inflation and unexpected industrial production. In line with Bianchi et al. (2016), we modify the original 6-factor model by replacing the S\&P GSCI Total Return Index with the equal-weighed commodity futures because the S\&P GSCI is over concentrated in energy sector (Erb and Harvey, 2006). The unexpected inflation and the unexpected industrial production at month $t$ are calculated as the difference between the time-series variable at month $t$ and its previous 12 month moving average.

Table 3 suggests that there are 3 regimes for the $F I_{J=60, K=1}$ but 2 regimes for the rest of trading strategies according to the BIC. For all the trading strategies, Regime 1 captures periods of crisis for investment returns, low Jansen's alpha $(\alpha)$ but relatively lower volatility $(\sigma)$. On the contrary, Regime 2 or 3 captures periods of exuberance when Jansen's alpha and profit volatility are both higher. The magnitude, statistical significance and sign of factor loadings vary under different market regimes. These findings confirm the existence of non-linearity relationships between investment returns and the risk factors, which were potentially missed by linear regression models (Bianchi et al., 2015,2016). The transition probabilities $\left(P_{11}, P_{22}, P_{33}\right)$ along with the durations $\left(D_{1}, D_{2}, D_{3}\right)$ indicate that exuberance regime is more persistent than the crisis regime with a few exceptions. The 6-factor model of Fuertes et al. (2010) explains the investment returns of $C C_{J=48, K=15}, J T_{J=3, K=1}$ and $G H_{J=12, K=1}$ across different market regimes, as the Jensen's alphas turn to negative or insignificant and a number of the risk factors have significant coefficients. While, the 6 -factor model fails to explain the return of $F I_{J=60, K=1}$ under the exuberance regime. The return on equal-weighted commodity futures cannot explain the investment returns of $C C_{J=48, K=15}, J T_{J=3, K=1}$ and $G H_{J=12, K=1}$ under the exuberance regime but explains the abnormal return under crisis regime. Overall, the 6-factor model shows superior ability in explaining the trading profitability than the return on equal-weighted commodity futures. ${ }^{14}$

\footnotetext{
${ }^{12}$ We do not present the Information ratio because the $t$-statistic of Jansen's alpha equals Information ratio multiplied by the square root of number of observations (Goodwin, 1998), hence their performance rankings are consistent with each other.

${ }^{13}$ See more technical discussion in Hamilton (1989) and Ang and Timmermann (2012).

${ }^{14}$ As a robustness check, we also augmented the 6-factor model by adding the term structure factor (Basu and Miffre, 2013; Bianchi et al., 2016). The findings are qualitatively the same are available upon request from the corresponding author.
} 
[Table 3 about here]

Table 4 presents the multiple non-temporal thresholds regression results of 2 single-factor models ${ }^{15}$ in the spirit of Equation (8). Panel A shows that there are 2 thresholds (3 regimes) for $G H_{J=12, K=1}, 1$ threshold ( 2 regimes) for $C C_{J=48, K=15}$ and $F I_{J=60, K=1}$, and 0 threshold ( 1 regime) for $J T_{J=3, K=1}$, when the market condition is measured by global funding liquidity (proxied by the TED spread). ${ }^{16}$ The Jensen's alphas of $C C_{J=48, K=15}, F I_{J=60, K=1}$ and $G H_{J=12, K=1}$ are higher and significant when the TED spread exceeds certain levels. This implies that the strategies of $C C_{J=48, K=15}, F I_{J=60, K=1}$ and $G H_{J=12, K=1}$ are more profitable relative to equal-weighted commodity futures and S\&P 500 when the global funding liquidity lower than certain levels. Panel B suggests the investment returns are insensitive to the uncertainty of the US stock market, as there is no statistically significant threshold value when threshold variable is measured by VIX. Panel $C$ reports that there is 1 threshold ( 2 regimes) for $C C_{J=48, K=15}$ and $J T_{J=3, K=1}$ but 0 threshold for the $F I_{J=60, K=1}$ and $G H_{J=12, K=1}$, when the threshold variable is measured by market sentiment. ${ }^{17}$ The superior profitability of $C C_{J=48, K=15}$ relative to equalweighted commodity futures is significant and higher when market sentiment is lower than a certain level. By contrast, the profitability of $J T_{J=3, K=1}$ compare to equal-weighted commodity futures is only significant when market sentiment above a certain level. Panel D suggests that $C C_{J=48, K=15}$ is more profitable relative to equally-weighted commodity futures (S\&P 500) when the term structure is above (below) a certain level. The profitability of $J T_{J=3, K=1}$ will be significantly enhanced relative to equallyweighted commodity futures and S\&P 500 when term structure exceeds certain level. The other two strategies are insensitive to the level of term structure.

[Table 4 about here]

Overall, the findings in Tables 3 and 4 are roughly consistent with momentum literature in equity market (Barroso and Santa-Clara, 2015; Daniel and Moskowitz, 2016), which suggests that the crash of momentum returns are somewhat predictable. However, momentum returns do not crash simultaneously, which means investors could diversify/hedge their invest risks by applying different version of momentum strategies.

\subsection{Relationship between different investment returns}

To explore whether these best performing investment strategies $\left(C C_{J=48, K=15}, F I_{J=60, K=1}, J T_{J=3, K=1}\right.$, $\left.G H_{J=12, K=1}\right)$ are interrelated by nature, Table 5 presents 20 regression results of the best strategies' returns as dependent variables regressed against a number of risk factors. Table 5 indicates that $F I_{J=60, K=1}\left(J T_{J=3, K=1}\right)$ can be largely explained by $C C_{J=48, K=15}\left(G H_{J=12, K=1}\right)$ as the regression intercept is statistically insignificant and the adjusted $R^{2}$ is about $0.20(0.40)$. However, the profitability of $C C_{J=48, K=15}\left(G H_{J=12, K=1}\right)$ cannot be explained by $F I_{J=60, K=1}\left(J T_{J=3, K=1}\right)$. The $J T_{J=3, K=1}$ and $G H_{J=12, K=1}$ are more closely associated with the US stock market momentum than $C C_{J=48, K=15}$ and $F I_{J=60, K=1}$, since the coefficient $\beta_{U M D}$ for $J T_{J=3, K=1}$ and $G H_{J=12, K=1}$ are statistically significant and

\footnotetext{
15 The intercept of single-factor model is the Jensen's alpha of each strategy.

16 The TED spread $=3$-month LIBOR rate -3 -month T-bill interest rate.

17 The monthly sentiment factor covers the period from January 1979 to November 2015, is collected from Jeffrey Wurgler's NYU website at http://people.stern.nyu.edu/jwurgler/. The monthly US stock market momentum factor is collected from Kenneth French's website at http://mba.tuck.dartmouth.edu/pages/faculty/ken.french/data_library.html, and covers the full sample.
} 
higher in terms of magnitudes. Apart from $C C_{J=48, K=15}$, the time-series momentum factor ${ }^{18}$ cannot significantly explain the investment returns of the other strategies.

[Table 5 about here]

Table 6 presents the pairwise correlation matrix for the 4 best investment returns in Panel A, and the correlation between the 4 investment returns with conventional investment asset classes in Panel B. Panel A shows that $J T_{J=3, K=1}$ and $G H_{J=12, K=1}$ are more closely correlated (0.63) than $C C_{J=48, K=15}$ and $F I_{J=60, K=1}(0.44)$. Panel B suggests the 4 investment returns and S\&P 500 are significant negatively correlated with a value between - 0.12 and -0.16 , suggesting the inverse of GGR, JT, GH and S\&P 500 could hedge each other. The investment strategy of $C C_{J=48, K=15}$ could be a diversifier for the US government bond and a hedger for global equity market. The correlation between $F I_{J=60, K=1}$ and VIX is 0.11 , which is quite low and positive, suggesting $F I_{J=60, K=1}$ could be a diversifier for the uncertainty of the US stock market (Baur and Lucey, 2010). All the four investment returns show positive correlation with the time-series momentum. While the $J T_{J=3, K=1}$ and $G H_{J=12, K=1}$ have no statistically significant correlation with the conventional investment asset classes apart from S\&P 500, which is roughly consistent with Bianchi et al. (2016). Overall, the findings by now suggests the $C C_{J=48, K=15}$ and $F I_{J=60, K=1}$ are quite different from $J T_{J=3, K=1}$ and $G H_{J=12, K=1}$ by nature.

[Table 6 about here]

\subsection{Seasonality of investment returns}

Previous studies have found that momentum strategies tend to be less profitable in January in equity markets (Jegadeesh and Titman, 1993; George and Hwang, 2004). The seasonality behaviour of many commodity prices has also been studied in various literature (Fama and French, 1987; Dempster et al., 2008; Back et al., 2013). The theory of storage implies that periods of low levels of supply (i.e., before the harvesting months for agricultural commodities) are also months with relatively high commodity prices whereas months with sufficient supply (i.e., after the harvesting months) are months with relatively low commodity prices. However, whether the seasonality behaviour is the source of commodity momentum profit is under studied. Moreover, it remains unclear whether the seasonality behaviour is justified by the risk in that months. We study the monthly profitability of the 4 best strategies by using the GJRGARCH(1,1)-AR(1) model as shown in Equations (9). ${ }^{19}$

$$
\begin{gathered}
R_{P, t}=\alpha_{1} R_{P, t-1}+\alpha_{i} \sum_{i=J a n u a r y}^{\text {December }} M_{i}+\varepsilon_{P, t}, \quad \varepsilon_{P, t} \mid \Phi_{P, t-1} \sim N\left(0, h_{P, t}\right) \\
h_{P, t}=\beta_{0}+\beta_{1} h_{P, t-1}+\beta_{2} \varepsilon_{P, t-1}^{2}+\beta_{3} \varepsilon_{P, t-1}^{2} I_{t-1}
\end{gathered}
$$

Where, $R_{P, t}$ is the monthly return for portfolio $P$ at month $t$, dummy variable $M_{i}=1$ in month $i$, and 0 otherwise. There is no intercept term in the mean equation, so, $\alpha_{i}$ measures the average excess return in month $i$. The lag return term is incorporated to the mean equation to filter out possible first-order autocorrelation in the return series. $h_{P, t}$, a proxy for market risk, is the variance of $\varepsilon_{P, t}$ conditional upon the information set $\Phi$ in month $t-1$. In the variance equation, $I_{t}=1$ if $\varepsilon_{P, t}<0$ and 0 otherwise. If the seasonality of investment returns exists, at least one of the $\alpha_{i}$ will be statistically significant and the Wald-test would reject the null hypothesis that the coefficients of $\alpha_{\text {January }}$ through $\alpha_{\text {December }}$ are

\footnotetext{
${ }^{18}$ Following literature (Moskowitz et al., 2012; Kim et al., 2016), the equally-weighted time-series momentum factor (TSMOM) is based on $J=1, K=1$.

${ }^{19} \mathrm{We}$ apply the GARCH family model for two reasons. First, the ARCH test justify the application of GARCH model. Second, we want to study the possible link between risk and the calendar effect (Sun and Tong, 2010).
} 
jointly 0 . For instance, if the investment returns are less profitable in January, $\alpha_{\text {January }}$ would be significant and smaller than the rest of $\alpha_{i}$ in terms of magnitude. While a significant and positive $\beta_{3}$ indicate that the bad news tend to increase volatility more than good news. The asymmetric effect, also called leverage effect, is considered to capture a widely observed characteristic of financial assets that an expected fall in prices tends to increase volatility more than an unexpected increase in asset prices of the same magnitude.

In order to study whether risk is the driver of return seasonality, we also estimate the GJRGARCHAR(1)-mean model.

$$
\begin{aligned}
& R_{P, t}=\alpha_{1} R_{P, t-1}+\alpha_{i} \sum_{i=\text { January }}^{\text {December }} M_{i}+\alpha_{2} h_{P, t}+\varepsilon_{P, t}, \quad \varepsilon_{P, t} \mid \Phi_{P, t-1} \sim N\left(0, h_{P, t}\right) \\
& h_{P, t}=\beta_{0}+\beta_{1} h_{P, t-1}+\beta_{2} \varepsilon_{P, t-1}^{2}+\beta_{3} \varepsilon_{P, t-1}^{2} I_{t-1}
\end{aligned}
$$

If risk is the driver of the return seasonality, the conditional variance $h_{P, t}$ in Equation (10) should have explanatory power for the monthly dummies in the mean equation. That is, $\alpha_{2}$ is significant, $\alpha_{i}$ in Equation (10) would turn statistically insignificant or, the magnitudes of $\alpha_{i}$ would be smaller than in Equation (9) (Sun and Tong, 2010). A significant and positive $\alpha_{2}$ also suggest there is a positive relationship between risk and investment returns.

As a robustness check, we estimate various alternative GARCH models such as the GARCH $(1,1)$ model and the EGARCH(1,1) model of Nelson (1991) which permits positive and negative shocks to have different effects. Under EGARCH(1,1) the conditional variance is shown as Equation (11).

$$
\ln \left(h_{P, t}\right)=\beta_{0}+\beta_{E G A R C H, 1} \ln \left(h_{P, t-1}\right)+\beta_{E G A R C H, 2}\left[\frac{\left|\varepsilon_{P, t-1}\right|-\sqrt{2 / \pi}}{\sqrt{h_{P, t-1}}}\right]+\beta_{E G A R C H, 3} \frac{\varepsilon_{P, t-1}}{\sqrt{h_{P, t-1}}}
$$

The EGARCH model has the advantage of not needing to impose the non-negative constraint on the model parameters and also allowing for asymmetries in the relationship between returns and volatility. $\beta_{E G A R C H, 1}$ measures the persistence in conditional volatility. $\beta_{E G A R C H, 2}$ captures the magnitude or symmetric effect. $\beta_{E G A R C H, 3}$ measures the asymmetry effect. A significant and positive $\beta_{E G A R C H, 3}$ implies that positive shocks are more destabilizing than negative shocks.

[Table 7 about here]

Panel A of Table 7 reports the BIC for each GARCH model where the superior models for $C C_{J=48, K=15}$ are $\operatorname{EGARCH}(1,1)$ and $\operatorname{GARCH}(1,1)$-mean since they have the smallest BIC. The superior models for $F I_{J=60, K=1}$ are $\operatorname{EGARCH}(1,1)$ and $\operatorname{GJRGARCH}(1,1)$-mean. $\operatorname{GARCH}(1,1)-\mathrm{AR}(1)$ and $\operatorname{GARCH}(1,1)-$ $\operatorname{AR}(1)$-mean are the best for $J T_{J=3, K=1}$. While the best models for $G H_{J=12, K=1}$ are $\operatorname{GJRGARCH}(1,1)$ AR(1) and GJRGARCH(1,1)-AR(1)-mean, respectively. For the sake of brevity, we only report the coefficients for the best models. ${ }^{20}$

Panel B of Table 7 reports several investment implications. First, Equation (9) and the alternatives suggest that returns show December effect rather than January effect, which contrasts to the seasonality of momentum returns in equity market (Jegadeesh and Titman, 1993; George and Hwang, 2004). This is indicated by the fact that the Wald-statistics reject the null hypotheses that the excess returns across the 12 months are jointly equal to 0. Additionally, the investment returns in December are statistically significant and higher than the other months in terms of magnitude. However, there is no clear return

${ }^{20}$ The other models are also estimated and generate qualitatively similar results, which are available upon request from the corresponding author. 
seasonality in the other months. Second, the seasonality of returns can be largely explained by its risk, given that the superior returns in December turn insignificant or lower in magnitude after incorporating the conditional variance $h_{P, t}$ into the mean equation. Third, there is very weak asymmetric relationship between returns and volatility. For the EGARCH-type models, the asymmetric parameter $\beta_{E G A R C H, 3}$ is either insignificant or less than the symmetric parameter $\beta_{E G A R C H, 2}$ in terms of magnitude, implying that the positive leverage cannot dominates the symmetric effect. For the GJRGARCH-type models, the asymmetric parameter $\beta_{3}$ in the variance equations are consistently insignificant, suggesting that bad news does not necessarily increase the volatility of investment returns.

\subsection{Herding behaviour in commodity futures market}

Table 8 presents the estimation results of the herding behaviour from Equation (8) for the 29 commodity futures over the full sample on monthly and daily data, respectively. For monthly data, there is 1 statistically significant threshold ( 2 regimes) when the threshold variable is measured by MSCI global equity market index. There is no significant threshold for VIX, TED spread, equal-weighted commodity futures returns and S\&P 500. Moreover, none of the herding parameter $\gamma_{3}$ is significantly negative. For daily data, however, there are 2 significant thresholds (3 regimes) when the threshold variable is measured by VIX, TED spread, S\&P 500 and MSCI global equity index but no threshold for equalweighted commodity future returns. The herding parameter $\gamma_{3}$ is significantly negative when VIX exceeds 28.58 or S\&P 500 return is lower than $-0.56 \%$. Table 8 suggests that herding behaviour in commodity futures market is more likely to occur on a daily basis than on monthly basis, especially when the US stock market is in higher uncertainty which is roughly consistent with the findings of literature (Chiang and Zheng, 2010; Schmitt and Westerhoff, 2017) in equity markets. This is probably because stock market turmoil triggers panic and then produces a contagion effect, which causes herding behaviour in commodity futures market.

[Table 8 about here]

Table 9 shows the regression results of the herding behaviour for the winners and losers in the past 3 months based on the JT strategy. We report results for the JT strategy because there is no significant herding present for the GGR and GH strategies. In Table 9, the herding parameter $\gamma_{3}$ is significantly negative for past winners but not for losers especially when the monthly return on S\&P 500 higher than $3.66 \%$ or the return on MSCI exceeds $2.37 \%$, suggesting booming stock market triggers positive feedback trading among past winners in commodity futures.

[Table 9 about here]

\subsection{Transaction costs}

The investigation thus far does not consider the transaction costs for three reasons. First, transaction costs in futures market is quite low, ranging from $0.0004 \%$ to $0.033 \%$ per trade (Locke and Venkatesh, 1997; Marshall et al., 2012; Bianchi et al., 2015). By contrast, the transaction costs per trade in equity markets ranging from $0.5 \%$ (Jegadeesh and Titman, 1993) to 2.3\% (Lesmond et al., 2004). Second, the liquidity in futures market is very high, indicated by either high market depth or tiny bid-ask spread and price impact (Lesmond et al., 2004). Shorting a position is just as easy as longing one (Bianchi et al., 2015). Third, the number of commodity futures in this study is only 29 , much smaller than the hundreds or thousands of equities for momentum trading (Korajczyk and Sadka, 2004). Hence, transaction costs are believed to play less important role in deteriorating the profitability of momentum returns in commodity futures market (Bianchi et al., 2015,2016).

Table 10 presents the trading statistics for the best performing GGR pairs trading strategies. For $C C_{J=48, K=15}\left(F I_{J=60, K=1}\right)$, the position typically opens when prices diverge by $0.26(0.38)$ or more, which is about 5 times higher than GGR strategy in equity market (Gatev et al., 2006; Broussard and 
Vaihekoski, 2012). The average number of times a pair is opened in any 15 (1) months period is about 3.5 (1.33), equivalents to 2.8 (15.96) per annual. Each pair is held open for 194.75 (17.52) days, more than $60 \%$ of holding days, confirms the relatively long-term property of the GGR strategy. In a roundtrip fashion, each pair are opened and closed about 0.70 (0.27) times per 15 (1) months, equivalent to 0.56 (3.24) times per annual. As the portfolio turnover is the weighted average of individual pairs turnover, the annual turnover ratio for $C C_{J=48, K=15}\left(F I_{J=60, K=1}\right)$ is appropriate to 0.56 (3.24) times. Based on 37 commodity futures, Fuertes et al. (2010) estimate an average annual portfolio turnover of 9.24 times for momentum with term structure signal. Even taking the highest turnover ratio (10.38 times per annual) from Fuertes et al. (2010), the transaction cost is about $0.69 \%$ per annual (Bianchi et al., 2015,2016). Given our JT and GH trading strategies are somewhat comparable to Bianchi et al. (2016), we use the transaction cost of $0.69 \%$ per annual $(0.06 \%$ per month) to evaluate our momentum returns. Obviously, the transaction costs are too low to eliminate the profitability of momentum returns, in terms of either average monthly returns or Jensen's alpha, in commodity futures market.

\section{Conclusion}

This study investigates the profitability of the pairs trading strategy of Gatev et al. (2006) and the 52week high momentum strategy of George and Hwang (2004) in comparison to the conventional momentum strategy of Jegadeesh and Titman (1993) in 29 commodity futures for the 1979-2017 period.

The motivation of the paper is three-fold. The first is to study what is relationship between formationholding window and profitability of each trading strategy? We find the reversal strategies are consistently unprofitable under 189 formation-holding window but the inverse of GGR strategies are profitable for a large number of formation-holding windows, which contrast to the GGRpairs trading strategy literature. Complementing Bianchi et al. (2015) and Bianchi et al. (2016), we find the longterm reversal of momentum returns are statistically significant only under certain conditions, especially when the holding period is longer than 30 months associated with formation period longer than 36 months. The inverse of Gatev et al. (2006) is consistently profitable, with a few exceptions, when formation period is longer than 24 months. While the momentum strategies of Jegadeesh and Titman (1993) and George and Hwang (2004) are more profitable under the low-formation-low-holding or the high-formation-high-holding windows.

Our second motivation is to assess which one of the three strategies is more profitable and at what conditions? We find the three trading strategies are all profitable but at different formation-holding windows. Sharpe ratio, Sortino ratio and Information ratio suggest the inverse of GGR pairs trading are more profitable in the full sample and prior to 1998; thereafter, the outperformance declines sharply. The Markov regime switching model and non-temporal threshold regression both indicate that even the most profitable tradingstrategies are quite sensitive to some partly predictable market conditions, such as the global funding liquidity and market sentiment. The profitability of the inverse of Gatev et al. (2006) cannot be explained by the momentum strategies of Jegadeesh and Titman (1993) or George and Hwang (2004). Similarly, the momentum profit of Jegadeesh and Titman (1993) or George and Hwang (2004) cannot be explained by the inverse returns of Gatev et al. (2006). However, they all report significant December effect rather than January effect. The third motivation of the paper is to test whether the momentum effects are associated with herding behaviour. Our results indicate that the winners of Jegadeesh and Titman (1993) are associated with herding when the monthly S\&P 500 return or the monthly GSCI World return exceeds certain level. There is no herding for the rest of strategies. At the aggregate commodity futures market, herding is more likely to occur on daily basis rather than monthly basis. Overall, our investigation suggests that the inverse strategy of Gatev et al. (2006) is quite different from Jegadeesh and Titman (1993) and George and Hwang (2004) in commodity futures market by nature, hence provide alternative trading strategies to investors. 


\section{Tables}

Table 1. Descriptive statistics of underlying S\&P GSCI indices on monthly data

Notes: This table divides the markets by sectors and includes the ticker symbol, exchange information and commencement dates of each commodity future. The basic descriptive statistics (monthly arithmetic mean in $\%$ term, standard deviation, skewness, and kurtosis) of excess returns are also presented. The simple monthly returns are calculated using end-of-month prices. All commodity futures used in this sample are published by Standard and Poor's. All price time-series end at 31/10/2017.

\begin{tabular}{|c|c|c|c|c|c|c|c|c|}
\hline Sector & Commodity & Ticker & Exchange & Start date & Mean & Std. dev. & Skewness & Kurtosis \\
\hline \multicolumn{9}{|l|}{ Energy } \\
\hline $\begin{array}{l}(1) \\
(2)\end{array}$ & $\begin{array}{l}\text { Brent crude } \\
\text { Gas oil }\end{array}$ & $\begin{array}{l}\text { SPGSBRP } \\
\text { SPGSGOP }\end{array}$ & $\begin{array}{l}\text { ICE (UK) } \\
\text { ICE (UK) }\end{array}$ & 06/01/1999 & $\begin{array}{l}0.96 \\
0.99\end{array}$ & $\begin{array}{l}9.00 \\
9.19\end{array}$ & $\begin{array}{l}-0.16 \\
-0.05\end{array}$ & $\begin{array}{l}4.25 \\
3.87\end{array}$ \\
\hline (3) & Heating oil & SPGSHOP & NYMEX & $31 / 12 / 1982$ & 0.57 & 9.08 & 0.39 & 4.57 \\
\hline (4) & Natural gas & SPGSNGP & NYMEX & 07/01/1994 & -1.42 & 14.35 & 0.54 & 4.37 \\
\hline (5) & RBOB gas & SPGSHUP & NYMEX & 07/01/1988 & 1.12 & 9.80 & 0.40 & 5.54 \\
\hline (6) & WTI crude & SPGSCLP & NYMEX & 07/01/1987 & 0.56 & 9.46 & 0.37 & 5.14 \\
\hline \multicolumn{9}{|l|}{ Metal } \\
\hline (8) & Copper & SPGSICP & LME & 02/01/1979 & 0.65 & 7.61 & 0.28 & 6.23 \\
\hline (9) & Gold & SPGSGCP & COMEX & 02/01/1979 & 0.15 & 5.56 & 0.52 & 6.48 \\
\hline (10) & Lead & SPGSILP & LME & 06/01/1995 & 0.65 & 8.19 & 0.03 & 4.12 \\
\hline (11) & Nickel & SPGSIKP & LME & 08/01/1993 & 0.68 & 9.82 & 0.21 & 3.35 \\
\hline (12) & Palladium & SPGSPAP & NYMEX & $26 / 12 / 2008$ & 1.84 & 8.24 & -0.43 & 3.54 \\
\hline (13) & Platinum & SPGSPLP & NYMEX & 30/12/1983 & 0.38 & 6.39 & 0.00 & 6.32 \\
\hline (14) & Silver & SPGSSIP & COMEX & 02/01/1979 & 0.36 & 9.47 & 0.69 & 8.27 \\
\hline (15) & Tin & SPGCISP & LME & 23/04/2007 & 0.64 & 7.95 & 0.23 & 3.53 \\
\hline$(16)$ & Zinc & SPGSIZP & LME & 08/01/1991 & 0.20 & 7.13 & -0.03 & 5.01 \\
\hline \multicolumn{9}{|c|}{ Agriculture \& Live Stock } \\
\hline (17) & Cocoa & SPGSCCP & ICE (US) & 06/01/1984 & -0.30 & 8.14 & 0.55 & 4.18 \\
\hline (18) & Coffee & SPGSKCP & ICE (US) & 07/01/1981 & 0.03 & 10.60 & 1.13 & 6.24 \\
\hline (19) & Corn & SPGSCNP & СBOT & 02/01/1979 & -0.18 & 7.55 & 1.14 & 8.44 \\
\hline (20) & Cotton & SPGSCTP & ICE (US) & 02/01/1979 & 0.04 & 6.93 & 0.38 & 4.33 \\
\hline (21) & Feeder cattle & SPGSFCP & CME & 07/01/2002 & 0.26 & 4.72 & -0.11 & 3.79 \\
\hline (22) & Lean hogs & SPGSLHP & CME & 02/01/1979 & -0.03 & 7.22 & -0.03 & 3.39 \\
\hline (23) & Live cattle & SPGSLCP & CME & 02/01/1979 & 0.36 & 4.97 & -0.08 & 4.98 \\
\hline (24) & Soybean & SPGSSOP & CBOT & 02/01/1979 & 0.55 & 8.06 & 1.47 & 11.38 \\
\hline (25) & Soybean meal & SPGSSMP & CBOT & $07 / 05 / 2012$ & 0.99 & 8.72 & 1.05 & 4.35 \\
\hline
\end{tabular}




\begin{tabular}{|lllllllll|}
\hline$(26)$ & Soybean oil & SPGSBOP & CBOT & $07 / 01 / 2005$ & 0.15 & 7.11 & -0.20 & 4.98 \\
$(27)$ & Sugar & SPGSSBP & ICE (US) & $02 / 01 / 1979$ & 0.22 & 11.45 & 1.13 & 6.94 \\
$(28)$ & Wheat Chicago & SPGSWHP & CBOT & $02 / 01 / 1979$ & -0.16 & 7.90 & 0.71 & 5.89 \\
$(29)$ & Wheat Kansas & SPGSKWP & KCBT & $06 / 01 / 1999$ & -0.44 & 8.28 & 0.52 & 4.65 \\
\hline
\end{tabular}

Table 2. Performances of different trading strategies over the full sample

Notes: This table displays results of equal-weighted monthly portfolio return series under different trading strategies over the full sample period from January 1979 to October 2017. $J$ is portfolio formation period, $K$ is portfolio holding period. The Best (Worst) portfolio for each trading strategy is based on the magnitude of average monthly excess return. The Mean column shows the arithmetic average value of each performance measure across the 189 formation-holding $(9 \times 21)$ combinations. The values in parentheses are the $t$-statistic based on Newey-West standard errors. Sharpe ratio is the average excess return per unit of volatility (measured by standard deviation of excess return). Sortino ratio modifies Sharpe ratio by replacing the volatility by using the excess return's standard deviation of negative observations. Upside potential ratio modifies the Sortino ratio by replacing the mean excess return with the higher partial moment of order one (focusing on positive derivations from the minimal acceptable return, 0 in this paper). Calmar ratio modifies the Sharpe ratio by replacing the volatility of excess return with the maximum drawdown (the largest negative cumulative excess return). VaR is the variance-covariance Value at Risk at $95 \%$ confidence level. Information ratio is calculated relative to the S\&P GSCI and the equal-weighed 29 S\&P GSCI commodity futures, respectively. Jensen's alpha is calculated relative to the S\&P GSCI, equal-weighed 29 commodity futures and S\&P 500 index, respectively. *** significant at $1 \%$ level. ** significant at 5\% level. * significant at $10 \%$ level. See Zhang et al. (2018) for more detailed discussion on performance measurement. The GRS statistic of Gibbons et al. (1989) testing whether the Jensen's alpha of the 4 best investment returns $\left(C C_{J=48, K=15}, F I_{J=60, K=1}, J T_{J=3, K=1}\right.$ and $\left.G H_{J=12, K=1}\right)$ are jointly 0 .

\begin{tabular}{|c|c|c|c|c|c|c|c|}
\hline & \multicolumn{3}{|c|}{ Gatev et al. (2006): committed capital } & \multicolumn{3}{|c|}{ Gatev et al. (2006): fully invested } & \multirow[t]{2}{*}{ GSCI } \\
\hline & Best & Worst & Mean & Best & Worst & Mean & \\
\hline & $C C_{J=48, K=15}$ & $C C_{J=3, K=1}$ & & $F I_{J=60, K=1}$ & $F I_{J=1, K=48}$ & & \\
\hline $\begin{array}{l}\text { Average monthly excess } \\
\text { return }(\%)\end{array}$ & $\begin{array}{l}0.25^{* * *} \\
(2.88)\end{array}$ & $\begin{array}{l}-0.08 \\
(-0.73)\end{array}$ & 0.11 & $\begin{array}{l}0.71 * * * \\
(2.65)\end{array}$ & $\begin{array}{l}-0.05 \\
(-0.22)\end{array}$ & 0.25 & $\begin{array}{l}0.10 \\
(0.35)\end{array}$ \\
\hline Sharpe ratio & 0.15 & -0.04 & 0.09 & 0.13 & -0.01 & 0.08 & 0.02 \\
\hline Sortino ratio & 0.20 & -0.05 & 0.13 & 0.17 & -0.02 & 0.11 & 0.03 \\
\hline Upside potential ratio & -0.86 & -1.21 & -0.97 & -0.93 & -0.99 & -0.78 & 1.06 \\
\hline Calmar ratio & -0.01 & 0.004 & -0.01 & -0.02 & 0.00 & -0.01 & -0.00 \\
\hline Excess return on $95 \%$ VaR & -0.09 & 0.02 & -0.05 & -0.08 & 0.01 & -0.05 & -0.01 \\
\hline Information ratio (S\&P GSCI) & 0.14 & -0.03 & 0.09 & 0.13 & -0.01 & 0.07 & / \\
\hline Jensen's alpha (S\&P GSCI) & $\begin{array}{l}0.25^{* * *} \\
(2.88)\end{array}$ & $\begin{array}{l}-0.08 \\
(-0.72)\end{array}$ & 0.11 & $\begin{array}{l}0.71 * * * \\
(2.64)\end{array}$ & $\begin{array}{l}-0.06 \\
(-0.25)\end{array}$ & 0.25 & l \\
\hline $\begin{array}{l}\text { Information ratio } \\
\text { (equal-weighted futures) }\end{array}$ & 0.14 & -0.04 & 0.08 & 0.13 & -0.02 & 0.07 & I \\
\hline $\begin{array}{l}\text { Jensen's alpha } \\
\text { (equal-weighted futures) }\end{array}$ & $\begin{array}{l}0.25 * * * \\
(2.95)\end{array}$ & $\begin{array}{l}-0.08 \\
(-0.77)\end{array}$ & 0.11 & $\begin{array}{l}0.71 * * * \\
(2.66)\end{array}$ & $\begin{array}{l}-0.09 \\
(-0.35)\end{array}$ & 0.23 & I \\
\hline Jensen's alpha (S\&P 500) & $0.32 * * *$ & $-0.26 * *$ & 0.14 & $0.88^{* * * *}$ & 0.11 & 0.30 & I \\
\hline
\end{tabular}




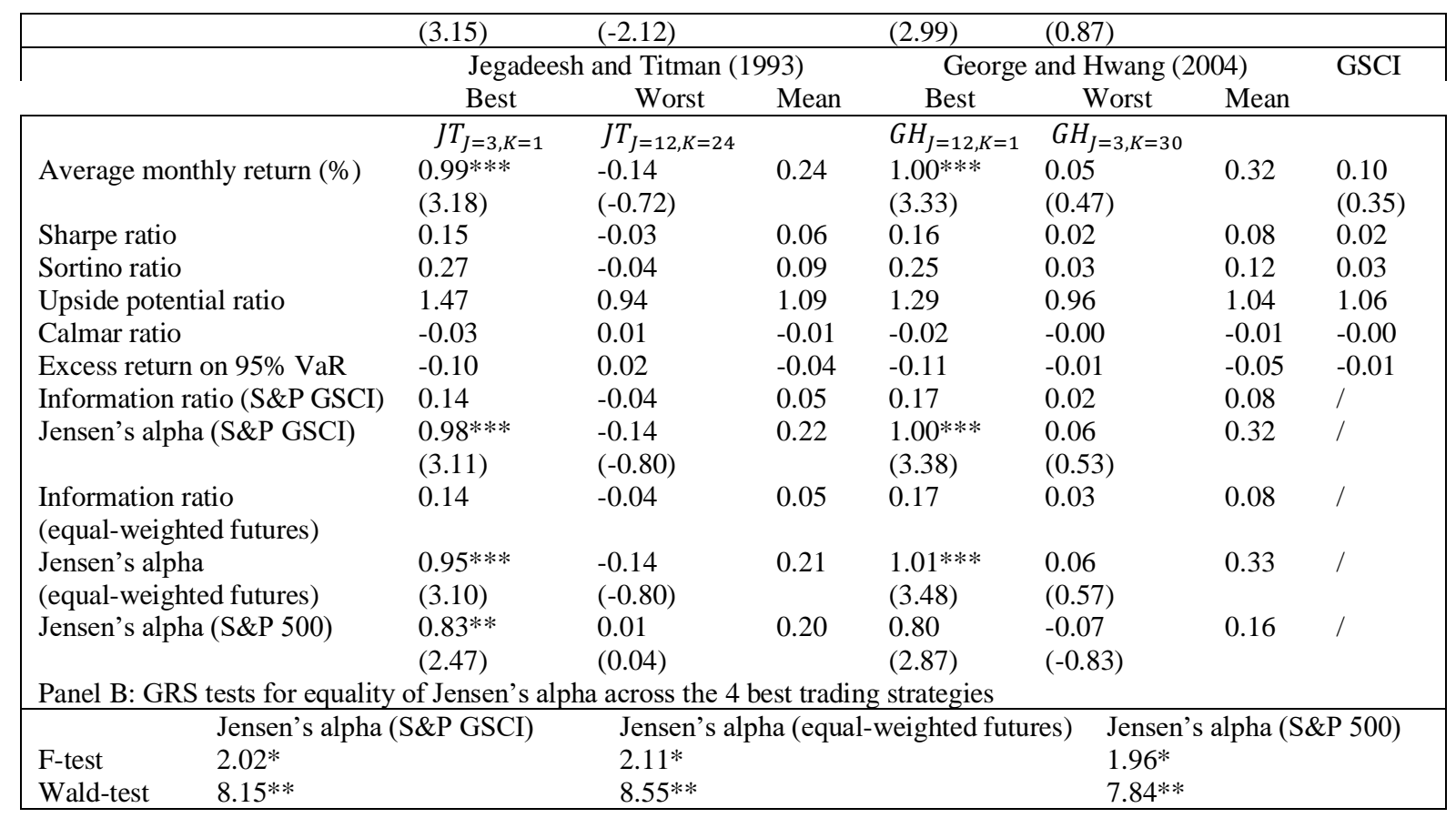

Table 3. Factor loadings for Markov regime switching regressions

Notes: $\alpha$ is the intercept of regression, which measures the Jensen's alpha. $\beta_{E W}, \beta_{S \& P 500}, \beta_{B o n d}, \beta_{F X}, \beta_{U I}$ and $\beta_{U I P}$ are the coefficients on the returns of equal-weighted commodity futures, S\&P 500, the US 10-year Government Bond, the US dollar effective exchange rate index, the US unexpected inflation and the unexpected changes in US industrial production, respectively. $\sigma_{s}, P_{s s}$ and $D_{s}$ stands for volatility, probability of staying in regime $s$, and duration of regime $s$, respectively. The subscript of $s$ stands for market regime. The number of market regimes is determined by minimizing the BIC. We test up to 3 market regimes.

\begin{tabular}{|c|c|c|c|c|c|c|c|c|}
\hline & & erse of $\mathrm{Ga}$ & et al. $(2($ & & Jegadees & Titman (1993) & George a & Iwang (2004) \\
\hline & $C C_{J}$ & $8, K=15$ & $F I_{J}$ & $0, K=1$ & & $K=1$ & & $2, K=1$ \\
\hline$\alpha_{1}$ & $-0.10^{*}$ & $-0.23 * *$ & 0.00 *** & -0.98 & 0.31 & -1.43 & -0.48 & -0.23 \\
\hline & $(-1.76)$ & $(-2.39)$ & (23.11) & $(-0.72)$ & $(0.86)$ & $(-1.51)$ & $(-0.65)$ & $(-0.27)$ \\
\hline$\beta_{E W, 1}$ & -0.05 & $-0.07 *$ & $-0.00 * *$ & 0.15 & $-0.33 * * *$ & $0.39 * *$ & $-1.04 * * *$ & $-1.78 * * *$ \\
\hline$r E W, 1$ & $(-1.44)$ & $(-1.75)$ & $(-2.43)$ & $(0.66)$ & $(-2.76)$ & $(2.20)$ & $(-2.98)$ & $(-8.38)$ \\
\hline$\beta_{S \& P 500,1}$ & & 0.02 & & -0.16 & & $0.49 * * *$ & & $-0.94 * * *$ \\
\hline & & $(0.66)$ & & $(-0.77)$ & & $(8.90)$ & & $(-4.21)$ \\
\hline$\beta_{\text {Bond }, 1}$ & & 0.02 & & 0.22 & & $-1.04 * * *$ & & $0.80 * *$ \\
\hline & & $(0.30)$ & & $(0.80)$ & & $(-5.37)$ & & $(2.52)$ \\
\hline$\beta_{F X, 1}$ & & 0.01 & & 0.17 & & $1.78 * * *$ & & $-1.18 * * *$ \\
\hline & & $(0.27)$ & & $(0.44)$ & & $(9.78)$ & & $(-4.17)$ \\
\hline$\beta_{U I, 1}$ & & -0.06 & & $-5.52 *$ & & -4.44 & & $6.36^{* * * *}$ \\
\hline & & $(-0.12)$ & & $(-1.93)$ & & $(-1.27)$ & & $(3.15)$ \\
\hline$\beta_{U I P, 1}$ & & -0.18 & & -0.98 & & $6.44 * * *$ & & $5.72 * * *$ \\
\hline & & $(-0.82)$ & & $(-0.66)$ & & $(6.02)$ & & $(10.36)$ \\
\hline$\alpha_{2}$ & $0.49 * * *$ & 0.21 & 0.60 & $-0.46^{*}$ & $1.28 *$ & 0.05 & $2.25 * * *$ & 0.36 \\
\hline & $(3.54)$ & (1.28) & $(1.05)$ & $(-1.75)$ & $(1.80)$ & $(0.11)$ & $(2.91)$ & $(0.90)$ \\
\hline$\beta_{E W, 2}$ & -0.00 & 0.04 & 0.10 & 0.20 & $1.01 * * *$ & $0.53 * * *$ & 0.30 & -0.02 \\
\hline & $(-0.12)$ & $(0.90)$ & $(0.99)$ & $(1.40)$ & $(4.09)$ & $(3.80)$ & (1.47) & $(-0.15)$ \\
\hline$\beta_{S \& P 500,2}$ & & $-0.09 * *$ & & -0.11 & & $-0.32 * * *$ & & $-0.13 *$ \\
\hline & & $(-2.47)$ & & $(-0.96)$ & & $(-3.39)$ & & $(-1.95)$ \\
\hline$\beta_{\text {Bond }, 2}$ & & 0.07 & & -0.01 & & 0.17 & & -0.07 \\
\hline & & (1.06) & & $(-0.12)$ & & $(0.95)$ & & $(-0.42)$ \\
\hline$\beta_{F X, 2}$ & & -0.11 & & 0.04 & & -0.22 & & -0.05 \\
\hline & & $(-1.35)$ & & $(0.28)$ & & $(-1.26)$ & & $(-0.30)$ \\
\hline$\beta_{U I, 2}$ & & $-1.19 * * *$ & & -0.90 & & $-2.76^{*}$ & & $-2.02 * *$ \\
\hline & & $(-3.52)$ & & $(-0.97)$ & & $(-1.86)$ & & $(-2.05)$ \\
\hline$\beta_{U I P, 2}$ & & 0.02 & & 0.54 & & $-1.16^{* *}$ & & -0.67 \\
\hline & & $(0.10)$ & & $(1.48)$ & & $(-2.07)$ & & $(-1.27)$ \\
\hline
\end{tabular}




\begin{tabular}{|c|c|c|c|c|c|c|c|c|}
\hline$\alpha_{3}$ & & & $\begin{array}{l}1.61 \\
(1.56)\end{array}$ & $\begin{array}{l}5.29 * * * \\
(8.77)\end{array}$ & & & & \\
\hline$\beta_{E W, 3}$ & & & $\begin{array}{l}-0.13 \\
(-0.44)\end{array}$ & $\begin{array}{l}0.08 \\
(0.19)\end{array}$ & & & & \\
\hline$\beta_{S \& P 500,3}$ & & & & $\begin{array}{l}-0.54 \\
(-1.24)\end{array}$ & & & & \\
\hline$\beta_{\text {Bond }, 3}$ & & & & $\begin{array}{l}-0.58 \\
(-1.18)\end{array}$ & & & & \\
\hline$\beta_{F X, 3}$ & & & & $\begin{array}{l}-0.45 \\
(-1.12)\end{array}$ & & & & \\
\hline$\beta_{U I, 3}$ & & & & $\begin{array}{l}-2.15 \\
(-0.88)\end{array}$ & & & & \\
\hline$\beta_{U I P, 3}$ & & & & $\begin{array}{l}1.33 \\
(1.63)\end{array}$ & & & & \\
\hline$\sigma_{1}$ & $0.63 * * *$ & $0.77 * * *$ & $9.07 * * *$ & $8.02 * * *$ & $4.29 * * *$ & $0.76^{* * *}$ & $4.85^{* * *}$ & $1.46 * * *$ \\
\hline$\sigma_{2}$ & $2.00 * * *$ & $1.95^{* * *}$ & $0.00 * * *$ & $1.69 * * *$ & $7.76 * * *$ & $5.78 * * *$ & $5.68 * * *$ & $4.99 * * *$ \\
\hline$\sigma_{3}$ & & & $3.70 * * *$ & $1.72 * * *$ & & & & \\
\hline$P_{11}$ & $0.96 * * *$ & $0.95 * * *$ & $0.70 * * *$ & $0.72 * * *$ & $0.86 * * *$ & $0.00 *$ & $0.65 * * *$ & $0.29 * *$ \\
\hline$P_{22}$ & $0.97 * *$ & $0.97 * * *$ & $0.61 * * *$ & $0.74 * * *$ & $0.82 * * *$ & $0.89 * * *$ & $0.73 * *$ & $0.94 * * *$ \\
\hline$P_{33}$ & & & $0.77 * * *$ & $0.34 *$ & & & & \\
\hline$D_{1}$ & $28.51 * *$ & $21.90 * * *$ & $3.36 * *$ & $3.56 * *$ & $7.10 * * *$ & $1.00 * * *$ & $2.82^{*}$ & $1.41 * * *$ \\
\hline$D_{2}$ & $34.26 * *$ & $34.04 * * *$ & $2.54 * * *$ & $3.85^{* * *}$ & $5.65^{*}$ & $9.14 * * *$ & $3.73 * *$ & $15.77 * * *$ \\
\hline$D_{3}$ & & & $4.34 * *$ & $1.51 * * *$ & & & & \\
\hline BIC & 3.52 & 3.90 & -39.10 & 6.35 & 6.59 & 6.62 & 6.49 & 6.45 \\
\hline
\end{tabular}

Table 4. Parameter estimates for multiple non-temporal threshold regressions

Notes: The TED spread $=3$-month LIBOR rate -3 -month T-bill interest rate. VIX is the Chicago Board Options Exchange market volatility index. Sentiment factor is collected from Jeffrey Wurgler's NYU website. The optimal number of threshold is selected by minimizing the BIC. The threshold values exclude the first and the last 10\% of the ordered sample.

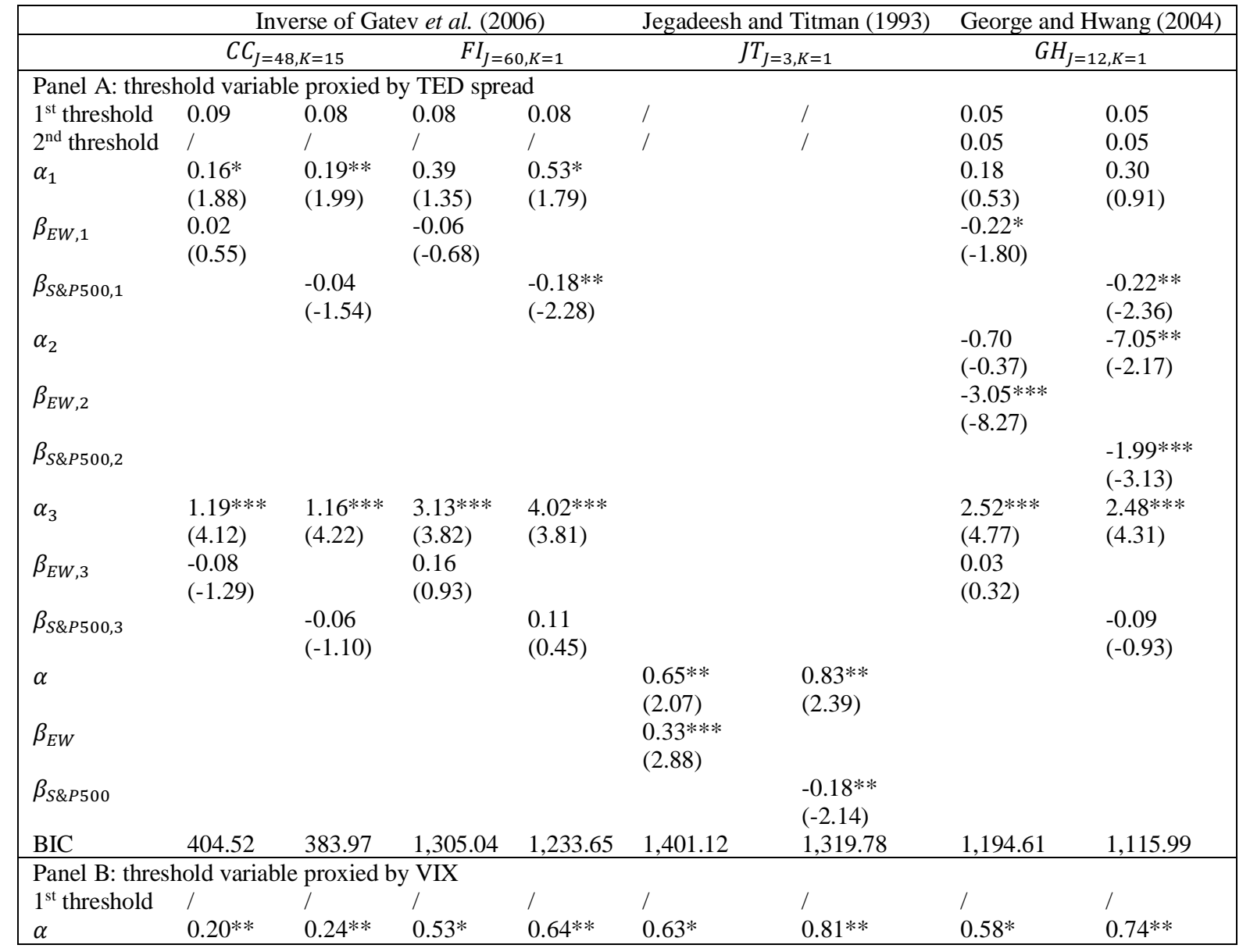




\begin{tabular}{|c|c|c|c|c|c|c|c|c|}
\hline$\beta_{E W}$ & $\begin{array}{l}(2.24) \\
-0.02 \\
(-0.68)\end{array}$ & $(2.53)$ & $\begin{array}{l}(1.78) \\
-0.04 \\
(-0.43)\end{array}$ & $(2.15)$ & $\begin{array}{l}(1.88) \\
0.32 * * * \\
(2.59)\end{array}$ & $(2.26)$ & $\begin{array}{l}(1.85) \\
-0.24 * * \\
(-2.27)\end{array}$ & $(2.42)$ \\
\hline$\beta_{S \& P 500}$ & & $\begin{array}{l}-0.06^{* *} \\
(-2.26)\end{array}$ & & $\begin{array}{l}-0.17 * * \\
(-2.19)\end{array}$ & & $\begin{array}{l}-0.20 * * \\
(-2.29)\end{array}$ & & $\begin{array}{l}-0.24 * * * \\
(-3.50)\end{array}$ \\
\hline BIC & 354.87 & 349.06 & $1,146.00$ & $1,140.60$ & $1,230.55$ & $1,236.49$ & $1,027.07$ & $1,024.14$ \\
\hline \multicolumn{9}{|c|}{ Panel C: threshold variable proxied by Sentiment } \\
\hline $1^{\text {st }}$ threshold & -0.37 & / & l & / & 0.46 & I & I & I \\
\hline$\alpha_{1}$ & $\begin{array}{l}0.67 * * \\
(2.11)\end{array}$ & & & & $\begin{array}{l}0.56 \\
(1.35)\end{array}$ & & & \\
\hline$\beta_{E W, 1}$ & $\begin{array}{l}-0.21 * * * \\
(-3.04)\end{array}$ & & & & $\begin{array}{l}0.50^{* * * *} \\
(3.56)\end{array}$ & & & \\
\hline \multicolumn{9}{|l|}{$\beta_{S \& P 500,1}$} \\
\hline$\alpha_{2}$ & $\begin{array}{l}0.27 * * * \\
(3.26)\end{array}$ & & & & $\begin{array}{l}1.78 * * * \\
(3.83)\end{array}$ & & & \\
\hline$\beta_{E W, 2}$ & $\begin{array}{l}0.02 \\
(0.90)\end{array}$ & & & & $\begin{array}{l}-0.10 \\
(-0.63)\end{array}$ & & & \\
\hline$\beta_{S \& P 500,2}$ & & & & & & & & \\
\hline$\alpha$ & & $\begin{array}{l}0.35 * * * \\
(3.64)\end{array}$ & $\begin{array}{l}0.77 * * * \\
(2.83)\end{array}$ & $\begin{array}{l}0.95 * * * \\
(3.07)\end{array}$ & & $\begin{array}{l}0.95 * * * \\
(2.62)\end{array}$ & $\begin{array}{l}1.06 * * * \\
(3.43)\end{array}$ & $\begin{array}{l}0.83 * * * \\
(2.67)\end{array}$ \\
\hline$\beta_{E W}$ & & & $\begin{array}{l}0.00 \\
(0.04)\end{array}$ & & & & $\begin{array}{l}-0.18 \\
(-1.61)\end{array}$ & \\
\hline$\beta_{S \& P 500}$ & & $\begin{array}{l}-0.05^{* *} \\
(-1.99)\end{array}$ & & $\begin{array}{l}-0.18^{* *} \\
(-2.27)\end{array}$ & & $\begin{array}{l}-0.18 * * \\
(-2.06)\end{array}$ & & $\begin{array}{l}-0.22 * * * \\
(-3.06)\end{array}$ \\
\hline $\mathrm{BIC}$ & 402.97 & 377.59 & $1,293.09$ & $1,162.76$ & $1,677.12$ & $1,240.77$ & $1,407.63$ & $1,022.37$ \\
\hline \multicolumn{9}{|c|}{ Panel D: threshold variable proxied by Term Structure } \\
\hline $1^{\text {st }}$ threshold & 8.73 & 8.47 & / & / & -2.49 & -2.49 & / & l \\
\hline $2^{\text {nd }}$ threshold & & & & & 5.14 & 7.52 & & \\
\hline$\alpha_{1}$ & $\begin{array}{l}0.16 * * \\
(1.98)\end{array}$ & $\begin{array}{l}0.22 * * \\
(2.43)\end{array}$ & & & $\begin{array}{l}-3.45 * * * \\
(-7.46)\end{array}$ & $\begin{array}{l}-3.32 * * * \\
(-5.81)\end{array}$ & & \\
\hline$\beta_{E W, 1}$ & $\begin{array}{l}-0.03 \\
(-1.24)\end{array}$ & & & & $\begin{array}{l}0.29 * \\
(1.94)\end{array}$ & & & \\
\hline$\beta_{S \& P 500,1}$ & & $\begin{array}{l}-0.04 * \\
(-1.65)\end{array}$ & & & & $\begin{array}{l}-0.01 \\
(-0.07)\end{array}$ & & \\
\hline$\alpha_{2}$ & $\begin{array}{l}0.94 * * * \\
(2.94)\end{array}$ & $\begin{array}{l}1.25^{* * *} * \\
(3.40)\end{array}$ & & & $\begin{array}{l}0.80 * * * \\
(2.81)\end{array}$ & $\begin{array}{l}1.57 * * * \\
(-5.81)\end{array}$ & & \\
\hline$\beta_{E W, 2}$ & $\begin{array}{l}0.10 \\
(0.86)\end{array}$ & & & & $\begin{array}{l}0.02 \\
(0.13)\end{array}$ & & & \\
\hline$\beta_{S \& P 500,2}$ & & $\begin{array}{l}-0.22 * * \\
(-2.54)\end{array}$ & & & & $\begin{array}{l}-0.08 \\
(-1.29)\end{array}$ & & \\
\hline$\alpha_{3}$ & & & & & $\begin{array}{l}6.46 * * * \\
(9.61)\end{array}$ & $\begin{array}{l}8.91 * * * \\
(8.09)\end{array}$ & & \\
\hline$\beta_{E W, 3}$ & & & & & $\begin{array}{l}0.83^{* * * *} \\
(3.78)\end{array}$ & & & \\
\hline$\beta_{S \& P 500,3}$ & & & & & & $\begin{array}{l}-1.34 * * * \\
(-4.53)\end{array}$ & & \\
\hline$\alpha$ & & & $\begin{array}{l}0.71 * * * \\
(2.72)\end{array}$ & $\begin{array}{l}0.88^{* * * *} \\
(2.99)\end{array}$ & & & $\begin{array}{l}1.01 * * * \\
(3.39)\end{array}$ & $\begin{array}{l}0.80 * * \\
(2.55)\end{array}$ \\
\hline$\beta_{E W}$ & & & $\begin{array}{l}0.01 \\
(0.08)\end{array}$ & & & & $\begin{array}{l}-0.19 * * \\
(-2.42)\end{array}$ & \\
\hline$\beta_{S \& P 500}$ & & & & $\begin{array}{l}-0.17 * * \\
(-2.21)\end{array}$ & & & & $\begin{array}{l}-0.21 * * * \\
(-2.80)\end{array}$ \\
\hline $\mathrm{BIC}$ & 405.43 & 383.05 & $1,364.62$ & $1,236.14$ & $1,637.32$ & $1,253.13$ & $2,657.03$ & $2,013.57$ \\
\hline
\end{tabular}


Table 5. Explanatory power of the different investment returns

Notes: $\beta_{C C_{J=48, K=15}}, \beta_{F I_{J=60, K=1}}, \beta_{J T_{J=3, K=1}}, \beta_{G H_{J=12, K=1}}, \beta_{U M D}$ and $\beta_{T S M O M}$ stand for coefficients on the investment returns of $C C_{J=48, K=15}, F I_{J=60, K=1}, J T_{J=3, K=1}, G H_{J=12, K=1}$, the US stock market and the equally-weighed time-series momentum factor, respectively. The monthly return on $U M D_{t}$ is from the Kenneth French's website.

\begin{tabular}{|c|c|c|c|c|c|c|c|c|c|c|}
\hline \multicolumn{11}{|c|}{ Panel A: The inverse of Gatev et al. (2006) } \\
\hline \multirow[b]{2}{*}{$\alpha$} & \multicolumn{5}{|c|}{$C C_{J=48, K=15}$} & \multicolumn{5}{|c|}{$F I_{J=60, K=1}$} \\
\hline & $\begin{array}{l}0.16^{* *} \\
(2.14)\end{array}$ & $\begin{array}{l}0.21 * * * \\
(2.68)\end{array}$ & $\begin{array}{l}0.18^{* *} \\
(2.01)\end{array}$ & $\begin{array}{l}0.22 * * * \\
(2.59)\end{array}$ & $\begin{array}{l}-0.29 \\
(-1.04)\end{array}$ & $\begin{array}{l}0.34 \\
(1.52)\end{array}$ & $\begin{array}{l}0.63 * * \\
(2.49)\end{array}$ & $\begin{array}{l}0.60 * * \\
(2.09)\end{array}$ & $\begin{array}{l}0.70 * * * \\
(2.57)\end{array}$ & $\begin{array}{l}-0.84 \\
(-1.10)\end{array}$ \\
\hline$\beta_{C C_{J=48, K=15}}$ & & & & & & $\begin{array}{l}1.44 * * * \\
(7.44)\end{array}$ & & & & \\
\hline$\beta_{F I_{J=60, K=1}}$ & $\begin{array}{l}0.14 * * * \\
(6.91)\end{array}$ & & & & & & & & & \\
\hline$\beta_{J T_{J=3, K=1}}$ & & $\begin{array}{l}0.05^{* * * *} \\
(3.04)\end{array}$ & & & & & $\begin{array}{l}0.11 * * * \\
(2.63)\end{array}$ & & & \\
\hline$\beta_{G H_{J=12, K=1}}$ & & & $\begin{array}{l}0.06 * * * \\
(3.77)\end{array}$ & & & & & $\begin{array}{l}0.12 * * * \\
(2.79)\end{array}$ & & \\
\hline$\beta_{U M D}$ & & & & $\begin{array}{l}0.06 * * * \\
(3.00)\end{array}$ & & & & & $\begin{array}{l}0.02 \\
(0.42)\end{array}$ & \\
\hline$\beta_{\text {TSMом }}$ & & & & & $\begin{array}{l}0.05^{*} \\
(1.73)\end{array}$ & & & & & $\begin{array}{l}0.14 * * \\
(2.01)\end{array}$ \\
\hline Adj. $R^{2}$ & 0.20 & 0.04 & 0.05 & 0.03 & 0.01 & 0.20 & 0.01 & 0.01 & -0.00 & 0.01 \\
\hline \multicolumn{11}{|c|}{ Panel B: Conventional momentum trading strategies } \\
\hline & \multirow{2}{*}{\multicolumn{5}{|c|}{$\begin{array}{c}\text { Jegadeesh and Titman (1993) } \\
J T_{J=3, K=1}\end{array}$}} & \multirow{2}{*}{\multicolumn{5}{|c|}{$\begin{array}{l}\text { George and Hwang (2004) } \\
\qquad G H_{I=12 K=1}\end{array}$}} \\
\hline & & & & & & & & & & \\
\hline$\alpha$ & $\begin{array}{l}0.58^{* *} \\
(2.15)\end{array}$ & $\begin{array}{l}0.63 * * \\
(2.19)\end{array}$ & $\begin{array}{l}0.22 \\
(0.85)\end{array}$ & $\begin{array}{l}0.84 * * * \\
(2.82)\end{array}$ & $\begin{array}{l}-3.09 * * \\
(-2.29)\end{array}$ & $\begin{array}{l}0.61 * * \\
(2.13)\end{array}$ & $\begin{array}{l}0.75 * * * \\
(2.72)\end{array}$ & $\begin{array}{l}0.47 * * \\
(1.98)\end{array}$ & $\begin{array}{l}0.91 * * * \\
(3.06)\end{array}$ & $\begin{array}{l}0.52 \\
(0.44)\end{array}$ \\
\hline$\beta_{C C_{J=48, K=15}}$ & $\begin{array}{l}0.79 * * * \\
(3.22)\end{array}$ & & & & & $\begin{array}{l}0.86^{* * * *} \\
(4.58)\end{array}$ & & & & \\
\hline$\beta_{F I_{J=60, K=1}}$ & & $\begin{array}{l}0.15^{* * * *} \\
(2.61)\end{array}$ & & & & & $\begin{array}{l}0.14 * * * \\
(2.64)\end{array}$ & & & \\
\hline$\beta_{J T_{J=3, K=1}}$ & & & & & & & & $\begin{array}{l}0.60 * * * \\
(10.86)\end{array}$ & & \\
\hline$\beta_{G H_{J=12, K=1}}$ & & & $\begin{array}{l}0.67 * * * \\
(9.20)\end{array}$ & & & & & & & \\
\hline$\beta_{U M D}$ & & & & $\begin{array}{l}0.24 * * * \\
(2.86)\end{array}$ & & & & & $\begin{array}{l}0.21 * * * \\
(3.46)\end{array}$ & \\
\hline
\end{tabular}




\begin{tabular}{|c|c|c|c|c|c|c|c|c|c|c|}
\hline $\begin{array}{l}\beta_{\text {TSMOM }} \\
\text { Adj. } R^{2}\end{array}$ & 0.04 & 0.01 & 0.40 & 0.02 & $\begin{array}{l}0.36^{* * * *} \\
(2.72) \\
0.01\end{array}$ & 0.05 & 0.01 & 0.40 & 0.02 & $\begin{array}{l}0.04 \\
(0.37 \\
0.00\end{array}$ \\
\hline
\end{tabular}

Table 6. Correlations of the 4 best investment returns

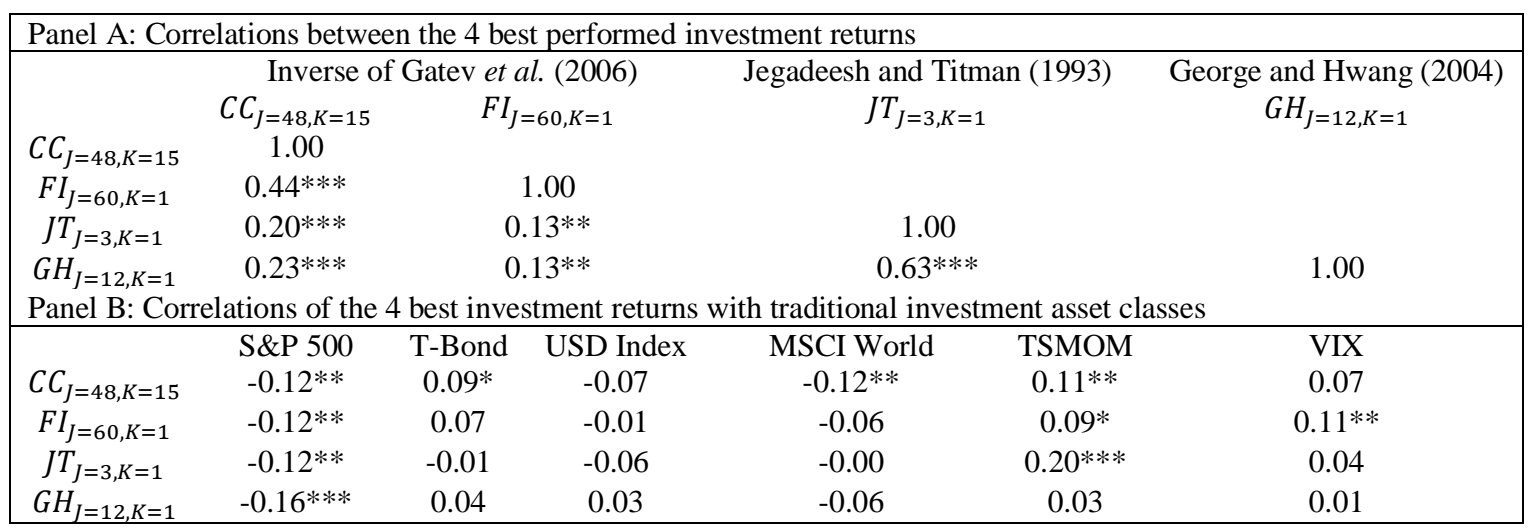


Table 7. Seasonality of investment returns

Notes: The regression analysis starts with GJRGARCH(1,1)-AR(1) and GJRGARCH(1,1)-AR(1)-mean as shown in Equations (9) and (10), respectively. We then estimate a number of the alternative models. The best GARCH model is identified by minimizing BIC. The lagged return is added to the mean equation to control the possible first-order autocorrelation in the return series. The Wald-statistic is computed under the null hypothesis that the returns in January through December are jointly equal to 0 .

\begin{tabular}{|c|c|c|c|c|c|c|c|c|}
\hline & \multicolumn{4}{|c|}{ Inverse of Gatev et al. (2006) } & \multirow{3}{*}{\multicolumn{2}{|c|}{$\frac{\text { Jegadeesh and Titman }}{J T_{J=3, K=1}}$}} & \multirow{2}{*}{\multicolumn{2}{|c|}{$\frac{\text { George and Hwang (2004) }}{G H_{J=12, K=1}}$}} \\
\hline & \multirow{2}{*}{\multicolumn{2}{|c|}{$\begin{array}{l}C C_{J=48, K=15} \\
\mathrm{CH} \text { models }\end{array}$}} & \multirow{2}{*}{\multicolumn{2}{|c|}{$F I_{J=60, K=1}$}} & & & & \\
\hline \multicolumn{3}{|c|}{ Panel A: BIC for GARCH models } & & & & & & \\
\hline GJRGARCH-AR & \multicolumn{2}{|c|}{$1,488.07$} & \multicolumn{2}{|c|}{$2,552.30$} & \multicolumn{2}{|c|}{$3,122.92$} & \multicolumn{2}{|c|}{$2,704.32$} \\
\hline GJRGARCH & \multicolumn{2}{|c|}{$1,482.15$} & \multicolumn{2}{|c|}{$2,551.07$} & \multicolumn{2}{|c|}{$3,123.10$} & \multicolumn{2}{|c|}{$2,712.57$} \\
\hline EGARCH & \multicolumn{2}{|c|}{$1,466.65$} & \multicolumn{2}{|c|}{$2,542.32$} & \multicolumn{2}{|c|}{$3,123.37$} & \multicolumn{2}{|c|}{$2,711.52$} \\
\hline GARCH-AR & \multicolumn{2}{|c|}{$1,482.80$} & \multicolumn{2}{|c|}{$2,566.89$} & \multicolumn{2}{|c|}{$3,117.99$} & \multicolumn{2}{|c|}{$2,705.79$} \\
\hline GARCH & \multicolumn{2}{|c|}{$1,476.76$} & \multicolumn{2}{|c|}{$2,565.58$} & \multicolumn{2}{|c|}{$3,118.12$} & \multicolumn{2}{|c|}{$2,716.64$} \\
\hline GJRGARCH-AR-M & \multicolumn{2}{|c|}{$1,489.49$} & \multicolumn{2}{|c|}{$2,555.80$} & \multicolumn{2}{|c|}{$3,128.70$} & \multicolumn{2}{|c|}{$2,709.15$} \\
\hline GJRGARCH-M & \multicolumn{2}{|c|}{$1,483.11$} & \multicolumn{2}{|c|}{$2,555.63$} & \multicolumn{2}{|c|}{$3,129.06$} & & \\
\hline EGARCH-M & & .23 & 2,5 & & & .56 & & \\
\hline GARCH-AR-M & & .29 & 2,5 & & & 1.03 & & \\
\hline GARCH-M & & .88 & 2,5 & & & .21 & & \\
\hline Panel B: Parameter es & imation & & & & & & & \\
\hline$\alpha_{t-1}$ & 1 & / & I & I & $\begin{array}{l}-0.02 \\
(-0.45)\end{array}$ & $\begin{array}{l}-0.02 \\
(-0.48)\end{array}$ & $\begin{array}{l}0.00 \\
(0.09)\end{array}$ & $\begin{array}{l}-0.02 \\
(-0.28)\end{array}$ \\
\hline$\alpha_{\text {January }}$ & $\begin{array}{l}-0.03 \\
(-0.47)\end{array}$ & $\begin{array}{l}-0.08 \\
(-0.58)\end{array}$ & $\begin{array}{l}0.82 * * * \\
(24.68)\end{array}$ & $\begin{array}{l}0.54 \\
(0.57)\end{array}$ & $\begin{array}{l}0.46 \\
(0.47)\end{array}$ & $\begin{array}{l}0.23 \\
(0.18)\end{array}$ & $\begin{array}{l}-0.15 \\
(-0.15)\end{array}$ & $\begin{array}{l}-0.87 \\
(-0.83)\end{array}$ \\
\hline$\alpha_{\text {Feburary }}$ & $\begin{array}{l}0.24 * * * \\
(2.78)\end{array}$ & $\begin{array}{l}0.25^{* *} * \\
(2.28)\end{array}$ & $\begin{array}{l}0.66 \\
(0.67)\end{array}$ & $\begin{array}{l}0.44 \\
(0.50)\end{array}$ & $\begin{array}{l}1.62 * * \\
(2.03)\end{array}$ & $\begin{array}{l}1.38 \\
(1.25)\end{array}$ & $\begin{array}{l}-0.42 \\
(-0.40)\end{array}$ & $\begin{array}{l}-1.18 \\
(-1.07)\end{array}$ \\
\hline$\alpha_{\text {March }}$ & $\begin{array}{l}0.00 \\
(0.01)\end{array}$ & $\begin{array}{l}-0.02 \\
(-0.15)\end{array}$ & $\begin{array}{l}0.56 \\
(0.45)\end{array}$ & $\begin{array}{l}0.46 \\
(0.50)\end{array}$ & $\begin{array}{l}-0.10 \\
(-0.12)\end{array}$ & $\begin{array}{l}-0.33 \\
(-0.30)\end{array}$ & $\begin{array}{l}0.81 \\
(0.61)\end{array}$ & $\begin{array}{l}0.01 \\
(0.00)\end{array}$ \\
\hline$\alpha_{\text {April }}$ & $\begin{array}{l}0.10 \\
(0.74)\end{array}$ & $\begin{array}{l}0.09 \\
(0.85)\end{array}$ & $\begin{array}{l}0.94 \\
(1.36)\end{array}$ & $\begin{array}{l}0.12 \\
(0.22)\end{array}$ & $\begin{array}{l}2.22 * * * \\
(2.91)\end{array}$ & $\begin{array}{l}1.98^{*} \\
(1.84)\end{array}$ & $\begin{array}{l}1.74 * * \\
(2.11)\end{array}$ & $\begin{array}{l}0.85 \\
(0.77)\end{array}$ \\
\hline$\alpha_{\text {May }}$ & $\begin{array}{l}0.02 * * * \\
(1,600)\end{array}$ & $\begin{array}{l}0.03 \\
(0.90)\end{array}$ & $\begin{array}{l}-0.62 \\
(-0.37)\end{array}$ & $\begin{array}{l}-1.38 \\
(-1.10)\end{array}$ & $\begin{array}{l}0.10 \\
(0.09)\end{array}$ & $\begin{array}{l}-0.12 \\
(-0.09)\end{array}$ & $\begin{array}{l}0.02 \\
(0.02)\end{array}$ & $\begin{array}{l}-0.74 \\
(-0.57)\end{array}$ \\
\hline$\alpha_{\text {June }}$ & $\begin{array}{l}0.05 * * * \\
(2,100)\end{array}$ & $\begin{array}{l}0.06 \\
(1.33)\end{array}$ & $\begin{array}{l}-0.00 \\
(-0.31)\end{array}$ & $\begin{array}{l}-0.67 \\
(-0.90)\end{array}$ & $\begin{array}{l}-0.05 \\
(-0.06)\end{array}$ & $\begin{array}{l}-0.31 \\
(-0.23)\end{array}$ & $\begin{array}{l}1.56 * * \\
(2.02)\end{array}$ & $\begin{array}{l}0.71 \\
(0.65)\end{array}$ \\
\hline$\alpha_{\text {July }}$ & $\begin{array}{l}0.06 \\
(0.90)\end{array}$ & $\begin{array}{l}0.08 \\
(1.24)\end{array}$ & $\begin{array}{l}0.85 \\
(1.24)\end{array}$ & $\begin{array}{l}0.81 \\
(1.11)\end{array}$ & $\begin{array}{l}-0.37 \\
(-0.30)\end{array}$ & $\begin{array}{l}-0.57 \\
(-0.40)\end{array}$ & $\begin{array}{l}0.39 \\
(0.39)\end{array}$ & $\begin{array}{l}-0.27 \\
(-0.23)\end{array}$ \\
\hline$\alpha_{\text {August }}$ & $0.08 * * *$ & 0.06 & 0.17 & 0.50 & 1.80 & 1.54 & 1.75 & 0.84 \\
\hline
\end{tabular}




\begin{tabular}{|c|c|c|c|c|c|c|c|c|}
\hline & $(2,300)$ & $(0.88)$ & $(0.20)$ & $(0.53)$ & (1.47) & $(0.96)$ & $(1.55)$ & $(0.54)$ \\
\hline$\alpha_{\text {September }}$ & $\begin{array}{l}-0.06 \\
(-0.90)\end{array}$ & $\begin{array}{l}-0.13^{* *} \\
(-1.96)\end{array}$ & $\begin{array}{l}-0.23 \\
(-0.35)\end{array}$ & $\begin{array}{l}-0.77 \\
(-1.26)\end{array}$ & $\begin{array}{l}0.81 \\
(0.74)\end{array}$ & $\begin{array}{l}0.55 \\
(0.37)\end{array}$ & $\begin{array}{l}0.13 \\
(0.12)\end{array}$ & $\begin{array}{l}-0.69 \\
(-0.53)\end{array}$ \\
\hline$\alpha_{\text {October }}$ & $\begin{array}{l}0.00 \\
(0.05)\end{array}$ & $\begin{array}{l}-0.04 \\
(-0.54)\end{array}$ & $\begin{array}{l}0.73 \\
(1.03)\end{array}$ & $\begin{array}{l}0.38 \\
(0.52)\end{array}$ & $\begin{array}{l}0.47 \\
(0.47)\end{array}$ & $\begin{array}{l}0.22 \\
(0.16)\end{array}$ & $\begin{array}{l}-0.62 \\
(-0.67)\end{array}$ & $\begin{array}{l}-1.47 \\
(-1.07)\end{array}$ \\
\hline$\alpha_{\text {November }}$ & $\begin{array}{l}0.04 * * * \\
(4,665)\end{array}$ & $\begin{array}{l}0.01 \\
(0.12)\end{array}$ & $\begin{array}{l}0.68 \\
(0.87)\end{array}$ & $\begin{array}{l}0.59 \\
(0.67)\end{array}$ & $\begin{array}{l}1.04 \\
(1.17)\end{array}$ & $\begin{array}{l}0.78 \\
(0.61)\end{array}$ & $\begin{array}{l}2.27 * * \\
(2.52)\end{array}$ & $\begin{array}{l}1.46 \\
(1.22)\end{array}$ \\
\hline$\alpha_{\text {December }}$ & $\begin{array}{l}0.29 * * * \\
(4.45)\end{array}$ & $\begin{array}{l}0.25 * * * \\
(3.69)\end{array}$ & $\begin{array}{l}1.95^{* *} \\
(2.28)\end{array}$ & $\begin{array}{l}1.70^{*} \\
(1.76)\end{array}$ & $\begin{array}{l}2.45 * * \\
(2.48)\end{array}$ & $\begin{array}{l}2.22 * \\
(1.81)\end{array}$ & $\begin{array}{l}2.61 * * * \\
(2.93)\end{array}$ & $\begin{array}{l}1.85 \\
(1.46)\end{array}$ \\
\hline$\alpha_{2}$ & & $\begin{array}{l}0.03^{* *} \\
(2.03)\end{array}$ & & $\begin{array}{l}0.01 \\
(1.31)\end{array}$ & & $\begin{array}{l}0.01 \\
(0.29)\end{array}$ & & $\begin{array}{l}0.03 \\
(1.03)\end{array}$ \\
\hline$\beta_{E G A R C H, 2}$ & $\begin{array}{l}0.77 * * * \\
(5.93)\end{array}$ & & $\begin{array}{l}0.51 * * \\
(2.08)\end{array}$ & & & & & \\
\hline$\beta_{E G A R C H, 3}$ & $\begin{array}{l}0.08 \\
(1.50)\end{array}$ & & $\begin{array}{l}0.30 * * \\
(2.01)\end{array}$ & & & & & \\
\hline$\beta_{3}$ & & & & $\begin{array}{l}0.83 \\
(1.37)\end{array}$ & & & $\begin{array}{l}0.19 \\
(1.52)\end{array}$ & $\begin{array}{l}0.19 \\
(1.33)\end{array}$ \\
\hline Wald-statistic & $3,200 * * *$ & $45.83 * * *$ & $689.74 * * *$ & 9.32 & $22.68 * *$ & 12.46 & $27.95 * * *$ & 15.51 \\
\hline
\end{tabular}

Table 8. Estimates of herding behaviour of aggregate commodity futures

Notes: This table shows the multiple non-temporal threshold regression results of Equation (8) using the 29 commodity futures over the full sample. The optimal number of threshold is determined by minimizing the BIC. The maximum number of threshold is up to 3 . A negative and statistically significant $\gamma_{3,5}$ would indicate the existence of herding. The subscript $s$ denotes for the regime.

\begin{tabular}{|c|c|c|c|c|c|c|c|c|c|c|}
\hline & \multicolumn{5}{|c|}{ Monthly data } & \multicolumn{5}{|c|}{ Daily data } \\
\hline $\begin{array}{l}\text { Threshold } \\
\text { variable }\end{array}$ & VIX & TED & $R_{E W}$ & $R_{S \& P 500}$ & $R_{M S C I}$ & VIX & TED & $R_{E W}$ & $R_{S \& P 500}$ & $R_{M S C I}$ \\
\hline $1^{\text {st }}$ threshold & I & I & I & I & 734.28 & 18.88 & 0.0016 & I & -0.56 & -0.75 \\
\hline $2^{\text {nd }}$ threshold & 1 & I & I & 1 & 1 & 28.58 & 0.0020 & 1 & 1.16 & 0.95 \\
\hline$\gamma_{0,1}$ & & & & & $4.46 * * *$ & $\begin{array}{l}0.91 * * * \\
(93.27)\end{array}$ & $\begin{array}{l}0.94^{* * * *} \\
(99.88)\end{array}$ & & $\begin{array}{l}0.98 * * * * \\
(61.94)\end{array}$ & $\begin{array}{l}0.98 \\
(50.21)\end{array}$ \\
\hline$\gamma_{1,1}$ & & & & & $\begin{array}{l}0.23 * * * * \\
(5.07)\end{array}$ & $\begin{array}{l}0.01 \\
(0.95)\end{array}$ & $\begin{array}{l}0.00 \\
(0.57)\end{array}$ & & $\begin{array}{l}0.07 * * * * \\
(4.97)\end{array}$ & $\begin{array}{l}0.10^{* * *} \\
(4.63)\end{array}$ \\
\hline$\gamma_{2,1}$ & & & & & $\begin{array}{l}0.18^{*} \\
(1.86)\end{array}$ & $\begin{array}{l}0.22 * * * \\
(6.83)\end{array}$ & $\begin{array}{l}0.26^{* * * *} \\
(8.86)\end{array}$ & & $\begin{array}{l}0.38^{* * * *} \\
(12.47)\end{array}$ & $\begin{array}{l}0.40^{* * * *} \\
(11.16)\end{array}$ \\
\hline$\gamma_{3,1}$ & & & & & $\begin{array}{l}0.02 * * \\
(2.13)\end{array}$ & $\begin{array}{l}0.05^{* *} \\
(2.52)\end{array}$ & $\begin{array}{l}0.02 \\
(0.98)\end{array}$ & & $\begin{array}{l}-0.01^{*} \\
(-1.81)\end{array}$ & $\begin{array}{l}-0.01 \\
(-0.95)\end{array}$ \\
\hline$\gamma_{0,2}$ & & & & & $\begin{array}{l}4.99 * * * * \\
(29.82)\end{array}$ & $\begin{array}{l}1.06^{* * * *} \\
(28.96)\end{array}$ & $\begin{array}{l}1.01^{* * * *} \\
(50.92)\end{array}$ & & $\begin{array}{l}0.93 * * * \\
(103.89)\end{array}$ & $\begin{array}{l}0.94 * * * \\
(120.41)\end{array}$ \\
\hline$\gamma_{1,2}$ & & & & & $\begin{array}{l}0.07 * * * * \\
(2.67)\end{array}$ & $\begin{array}{l}-0.02 \\
(-1.00)\end{array}$ & $\begin{array}{l}0.01 \\
(0.32)\end{array}$ & & $\begin{array}{l}-0.00 \\
(-0.56)\end{array}$ & $\begin{array}{l}0.01^{*} \\
(1.78)\end{array}$ \\
\hline$\gamma_{2,2}$ & & & & & $\begin{array}{l}0.17 * * \\
(2.53)\end{array}$ & $\begin{array}{l}0.16 \\
(1.22)\end{array}$ & $\begin{array}{l}-0.01 \\
(-0.19)\end{array}$ & & $\begin{array}{l}0.26 \text { **** } \\
(9.03)\end{array}$ & $\begin{array}{l}0.24 * * * \\
(10.10)\end{array}$ \\
\hline$\gamma_{3,2}$ & & & & & $\begin{array}{l}-0.00 \\
(-0.41)\end{array}$ & $\begin{array}{l}0.06 \\
(0.90)\end{array}$ & $\begin{array}{l}0.26 * * * * \\
(7.80)\end{array}$ & & $\begin{array}{l}0.04 * * \\
(2.24)\end{array}$ & $\begin{array}{l}0.04 * * \\
(2.49)\end{array}$ \\
\hline$\gamma_{0,3}$ & & & & & & $\begin{array}{l}1.08^{* * * *} \\
(39.68)\end{array}$ & $\begin{array}{l}0.99^{* * *} \\
(57.95)\end{array}$ & & $\begin{array}{l}1.07 * * * \\
(27.23)\end{array}$ & $\begin{array}{l}1.04 * * * \\
(40.43)\end{array}$ \\
\hline$\gamma_{1,3}$ & & & & & & $\begin{array}{l}0.04 * * * \\
(2.63)\end{array}$ & $\begin{array}{l}-0.01 \\
(-0.50)\end{array}$ & & $\begin{array}{l}-0.12 * * \\
(-2.45)\end{array}$ & $\begin{array}{l}-0.16^{* * * *} \\
(-3.04)\end{array}$ \\
\hline$\gamma_{2,3}$ & & & & & & $\begin{array}{l}0.41 * * * \\
(9.34)\end{array}$ & $\begin{array}{l}0.39^{* * * *} \\
(9.62)\end{array}$ & & $\begin{array}{l}0.19^{*} \\
(1.80)\end{array}$ & $\begin{array}{l}0.28 * * * * \\
(4.99)\end{array}$ \\
\hline$\gamma_{3,3}$ & & & & & & $\begin{array}{l}-0.03 * * * \\
(-2.62)\end{array}$ & $\begin{array}{l}-0.01 \\
(-0.58)\end{array}$ & & $\begin{array}{l}0.07 \\
(1.47)\end{array}$ & $\begin{array}{l}0.05^{*} \\
(1.80)\end{array}$ \\
\hline$\gamma_{0}$ & $\begin{array}{l}4.60 * * * \\
(32.46)\end{array}$ & $\begin{array}{l}4.65^{* * * *} \\
(35.72)\end{array}$ & $\begin{array}{l}4.69^{* * * *} \\
(37.79)\end{array}$ & $\begin{array}{l}4.59 * * * \\
(33.29)\end{array}$ & & & & $\begin{array}{l}0.95 * * * \\
(117.79)\end{array}$ & & \\
\hline$\gamma_{1}$ & $\begin{array}{l}0.09 * * * * \\
(3.24)\end{array}$ & $\begin{array}{l}0.10^{* * * *} \\
(3.56)\end{array}$ & $\begin{array}{l}0.13^{* * * *} \\
(4.81)\end{array}$ & $\begin{array}{l}0.09 * * * \\
(3.42)\end{array}$ & & & & $\begin{array}{l}0.01 \\
(1.13)\end{array}$ & & \\
\hline$\gamma_{2}$ & $\begin{array}{l}0.30 * * * \\
(4.51)\end{array}$ & $\begin{array}{l}0.30^{* * * *} \\
(4.72)\end{array}$ & $\begin{array}{l}0.21^{* * * *} \\
(3.62)\end{array}$ & $\begin{array}{l}0.31 * * * * \\
(4.70)\end{array}$ & & & & $\begin{array}{l}0.28 * * * \\
(11.56)\end{array}$ & & \\
\hline$\gamma_{3}$ & -0.01 & -0.01 & 0.00 & -0.01 & & & & 0.02 & & \\
\hline
\end{tabular}




\begin{tabular}{|c|c|c|c|c|c|c|c|c|c|c|}
\hline & $(-1.58)$ & $(-1.59)$ & $(0.43)$ & $(-1.63)$ & & & & (1.20) & & \\
\hline BIC & 308.14 & 357.55 & 481.18 & 345.54 & 480.16 & $-15,250$ & $-17,010$ & $-19,980$ & $-16,190$ & 20,130 \\
\hline
\end{tabular}

Table 9. Estimates of herding behaviour of the monthly JT momentum portfolios

Notes: This Table tests the herding behaviour for the winners and losers in the past 3 months $(J=3)$ based on the momentum strategy of Jegadeesh and Titman (1993). A negative and statistically significant $\gamma_{3,5}$ would indicate the existence of herding. The subscript $s$ denotes for the regime.

\begin{tabular}{|c|c|c|c|c|c|c|c|c|c|c|}
\hline & & & Winners & & & & & Losers & & \\
\hline $\begin{array}{l}\text { Threshold } \\
\text { variable }\end{array}$ & VIX & TED & $R_{E W}$ & $R_{S \& P 500}$ & $R_{M S C I}$ & VIX & TED & $R_{E W}$ & $R_{S \& P 500}$ & $R_{M S C I}$ \\
\hline $1^{\text {st }}$ threshold & I & I & 2.45 & 3.66 & 2.37 & I & I & -2.59 & I & I \\
\hline $2^{\text {nd }}$ threshold & I & I & 2.92 & I & 1 & I & I & 1.26 & I & I \\
\hline$\gamma_{0,1}$ & & & $\begin{array}{l}4.36 * * * \\
(21.56)\end{array}$ & $\begin{array}{l}4.66 * * * * \\
(21.84)\end{array}$ & $\begin{array}{l}4.24 * * * \\
(19.51)\end{array}$ & & & $\begin{array}{l}5.74 * * * * \\
(10.37)\end{array}$ & & \\
\hline$\gamma_{1,1}$ & & & $\begin{array}{l}0.12 * * * \\
(2.58)\end{array}$ & $\begin{array}{l}0.11 * * * \\
(4.84)\end{array}$ & $\begin{array}{l}0.17 * * * \\
(4.93)\end{array}$ & & & $\begin{array}{l}0.23 \\
(1.26)\end{array}$ & & \\
\hline$\gamma_{2,1}$ & & & $\begin{array}{l}0.16^{* *} \\
(2.04)\end{array}$ & $\begin{array}{l}-0.04 \\
(-0.50)\end{array}$ & $\begin{array}{l}0.08 \\
(0.91)\end{array}$ & & & $\begin{array}{l}-0.02 \\
(-0.05)\end{array}$ & & \\
\hline$\gamma_{3,1}$ & & & $\begin{array}{l}0.01^{*} \\
(1.66)\end{array}$ & $\begin{array}{l}0.02 * * * \\
(3.56)\end{array}$ & $\begin{array}{l}0.01 * * * \\
(2.92)\end{array}$ & & & $\begin{array}{l}0.01 * * \\
(2.01)\end{array}$ & & \\
\hline$\gamma_{0,2}$ & & & $\begin{array}{l}2.31 \\
(0.97)\end{array}$ & $\begin{array}{l}3.22 * * * * \\
(6.82)\end{array}$ & $\begin{array}{l}4.01 * * * \\
(11.01)\end{array}$ & & & $\begin{array}{l}4.75 * * * \\
(16.59)\end{array}$ & & \\
\hline$\gamma_{1,2}$ & & & $\begin{array}{l}-1.08^{*} \\
(-1.72)\end{array}$ & $\begin{array}{l}0.05 \\
(0.61)\end{array}$ & $\begin{array}{l}0.06 \\
(1.11)\end{array}$ & & & $\begin{array}{l}0.13^{* * *} \\
(1.99)\end{array}$ & & \\
\hline$\gamma_{2,2}$ & & & $\begin{array}{l}1.93 \\
(1.38)\end{array}$ & $\begin{array}{l}0.94 * * * \\
(3.43)\end{array}$ & $\begin{array}{l}0.50^{* * * *} \\
(4.23)\end{array}$ & & & $\begin{array}{l}-0.77 * * * \\
(-3.67)\end{array}$ & & \\
\hline$\gamma_{3,2}$ & & & $\begin{array}{l}0.02 \\
(0.48)\end{array}$ & $\begin{array}{l}-0.05 * * \\
(-2.04)\end{array}$ & $\begin{array}{l}-0.02 * * * \\
(-4.12)\end{array}$ & & & $\begin{array}{l}0.15^{* * * *} \\
(5.04)\end{array}$ & & \\
\hline$\gamma_{0,3}$ & & & $\begin{array}{l}3.05 * * * * \\
(4.36)\end{array}$ & & & & & $\begin{array}{l}4.42 * * * \\
(10.82)\end{array}$ & & \\
\hline$\gamma_{1,3}$ & & & $\begin{array}{l}-0.04 \\
(-0.18)\end{array}$ & & & & & $\begin{array}{l}0.02 \\
(0.24)\end{array}$ & & \\
\hline$\gamma_{2,3}$ & & & $\begin{array}{l}0.50 \\
(1.61)\end{array}$ & & & & & $\begin{array}{l}0.40^{* * *} \\
(2.04)\end{array}$ & & \\
\hline$\gamma_{3,3}$ & & & $\begin{array}{l}-0.00 \\
(-0.09)\end{array}$ & & & & & $\begin{array}{l}-0.03 \\
(-1.63)\end{array}$ & & \\
\hline$\gamma_{0}$ & $\begin{array}{l}4.52^{* * * * *} \\
(23.34)\end{array}$ & $\begin{array}{l}4.55 * * * \\
(22.11)\end{array}$ & & & & $\begin{array}{l}4.49 * * * \\
(21.37)\end{array}$ & $\begin{array}{l}4.41 * * * \\
(21.93)\end{array}$ & & $\begin{array}{l}4.38 * * * \\
(21.06)\end{array}$ & $\begin{array}{l}4.30^{* * * *} \\
(22.16)\end{array}$ \\
\hline$\gamma_{1}$ & $\begin{array}{l}0.10 * * * * \\
(4.08)\end{array}$ & $\begin{array}{l}0.11 * * * \\
(4.51)\end{array}$ & & & & $\begin{array}{l}0.04 \\
(1.34)\end{array}$ & $\begin{array}{l}0.05^{*} \\
(1.74)\end{array}$ & & $\begin{array}{l}0.05^{*} \\
(1.75)\end{array}$ & $\begin{array}{l}0.08 * * * \\
(2.63)\end{array}$ \\
\hline$\gamma_{2}$ & $\begin{array}{l}0.04 \\
(0.50)\end{array}$ & $\begin{array}{l}0.09 \\
(1.02)\end{array}$ & & & & $\begin{array}{l}0.15 * * \\
(1.99)\end{array}$ & $\begin{array}{l}0.18 * * \\
(2.31)\end{array}$ & & $\begin{array}{l}0.17 \text { ** } \\
(2.23)\end{array}$ & $\begin{array}{l}0.18 * * \\
(2.29)\end{array}$ \\
\hline$\gamma_{3}$ & $0.01 * * *$ & $0.01 * *$ & & & & -0.00 & -0.00 & & -0.00 & -0.00 \\
\hline
\end{tabular}




\begin{tabular}{|lllllllllll|}
\hline & $(2.67)$ & $(2.01)$ & & & & $(-0.05)$ & $(-0.30)$ & & $(-0.12)$ & $(-0.35)$ \\
BIC & 542.09 & 684.22 & 1002.67 & 615.44 & 951.62 & 510.41 & 631.45 & 849.61 & 568.94 & 812.66 \\
\hline
\end{tabular}

Table 10. Trading statistics for GGR pairs trading strategies

\begin{tabular}{|lll|}
\hline & $J=48, K=15$ & $J=60, K=1$ \\
Average price deviation trigger for opening pairs & 0.26 & 0.38 \\
Average number of times a pair is opened per $K$-month period & 3.50 & 1.33 \\
Average number of round-trip trades per pair & 0.70 & 0.27 \\
Average time pairs are open in trading days & 194.75 & 17.52 \\
\hline
\end{tabular}


Figure 1. Average monthly portfolio returns

Notes. This figure plots the arithmetic average monthly returns of the conventional pairs trading of Gatev et al. (2006) (Panels A and B), conventional momentum of Jegadeesh and Titman (1993) (Panel C), and 52-week high momentum of George and Hwang (2004) (Panel D). Capital committed (CC) and fully invested (FI) weighting scheme based GGR portfolio returns are calculated as the sum of pairs returns divided either by the number of pairs $(N=5)$ and the number of pairs that are open at any given date, respectively. The left-vertical axis reports the average monthly portfolio return in $\%$ term. The right-vertical axis reports the p-value for the corresponding average monthly portfolio return. The horizontal axis shows the holding periods based on any given formation period. The formation-holding window including any combination of 9 formation periods of 1 , $3,6,9,12,24,36,48$ and 60 months and 21 holding periods of $1,3,6,9,12,15,18,21,24,27,30,33,36,39,42,45,48,51$, 54,57 and 60 months. A statistically significant positive return for momentum-like strategy means loss for reversal-like strategy.

Panel A: Conventional GGR pairs trading based on Capital Committed (CC) weighing scheme 
J=1 Full Sample
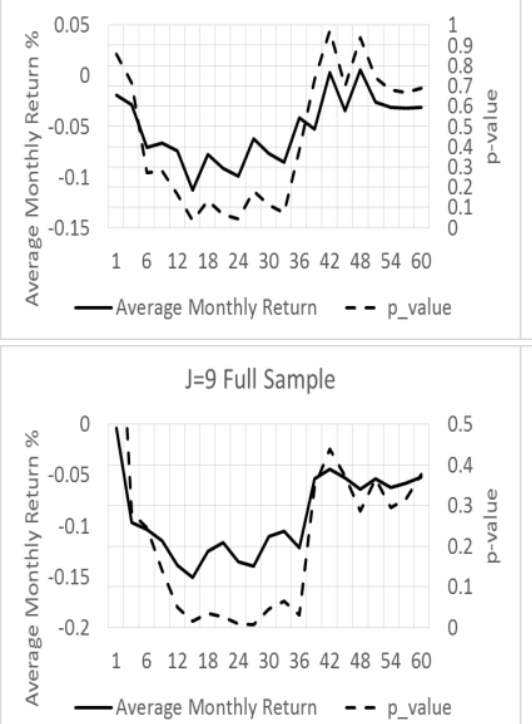

J=36 Full Sample

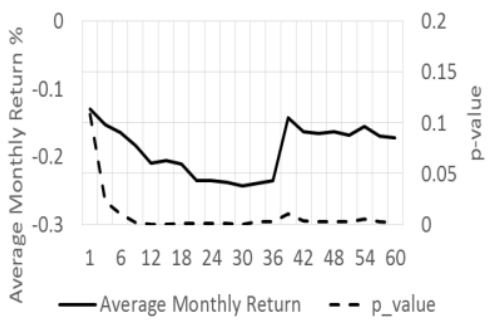

J=3 Full Sample

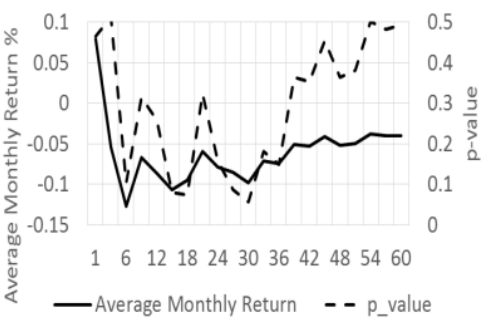

$\mathrm{J}=12$ Full Sample

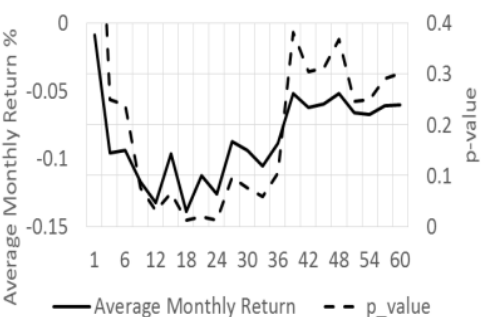

J=48 Full Sample

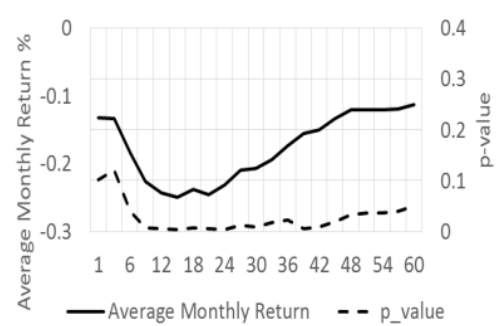

$J=6$ Full Sample

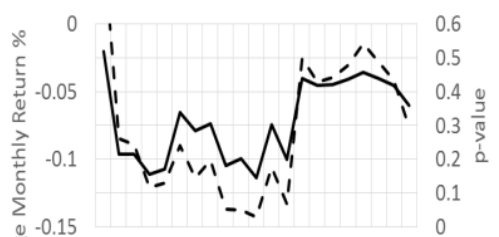

$16 \quad 121824303642485460$

—Average Monthly Return - - p_value

J=24 Full Sample

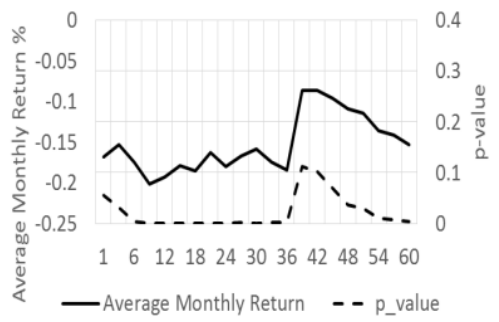

J=60 Full Sample

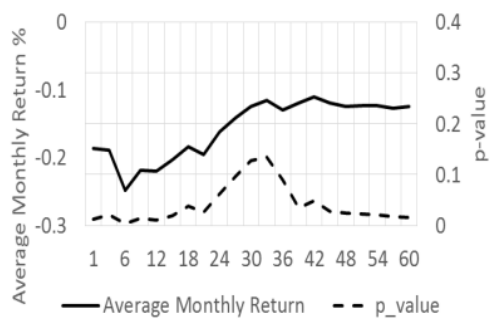

Panel B: Conventional GGR pairs trading based on Fully Invested (FI) weighing scheme

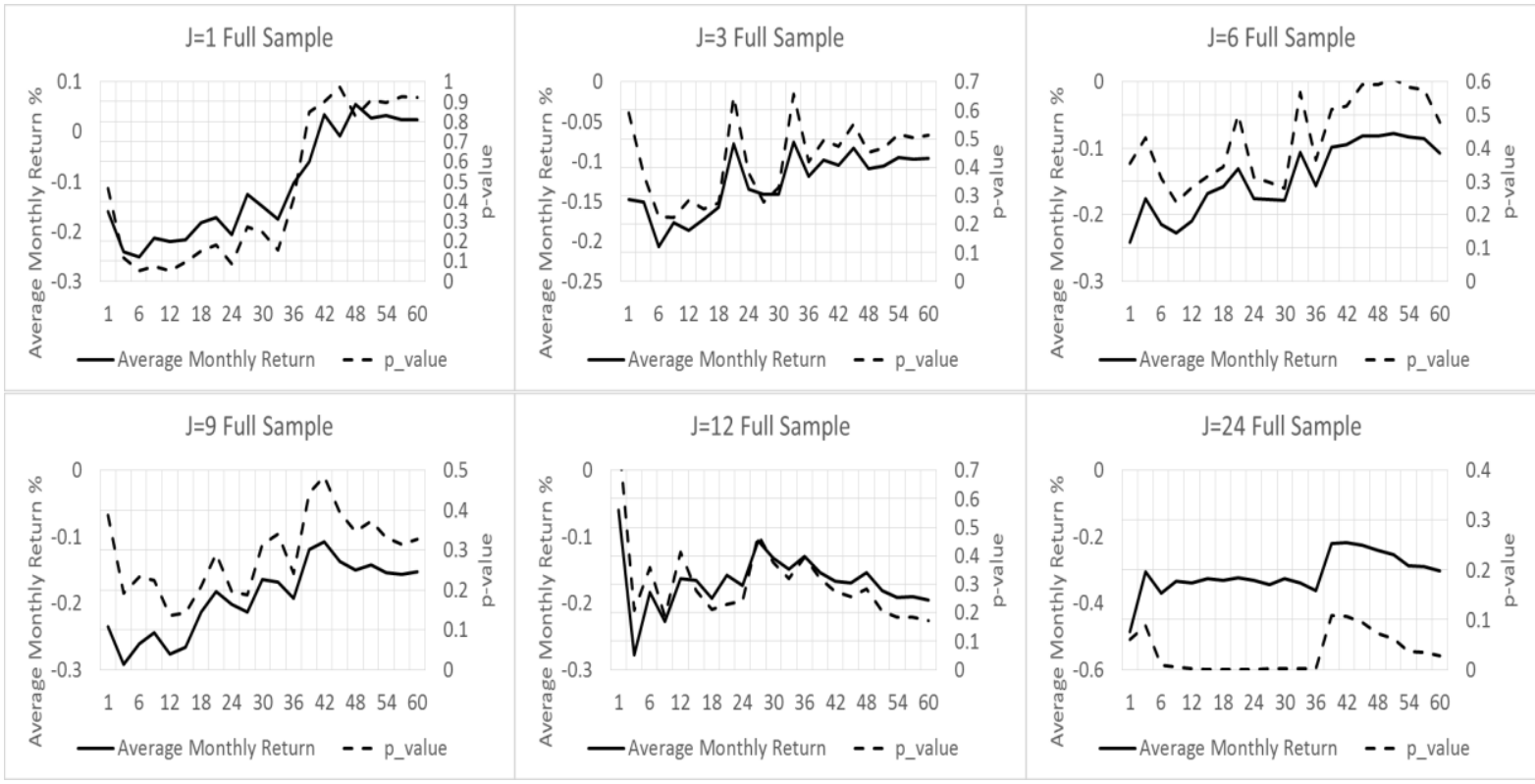




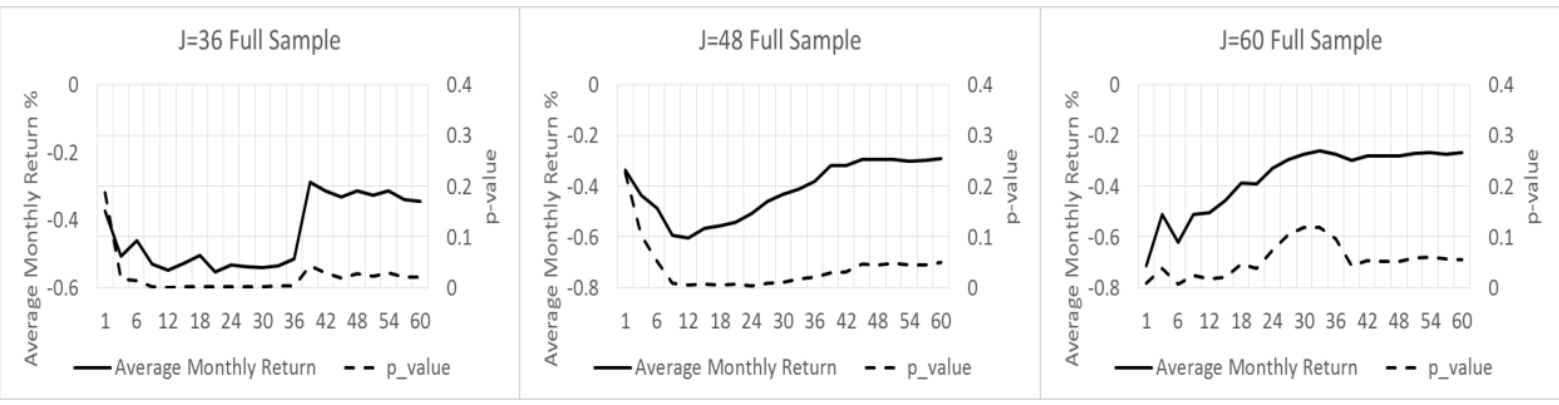

Panel C: Conventional momentum strategy of Jegadeesh and Titman (1993)

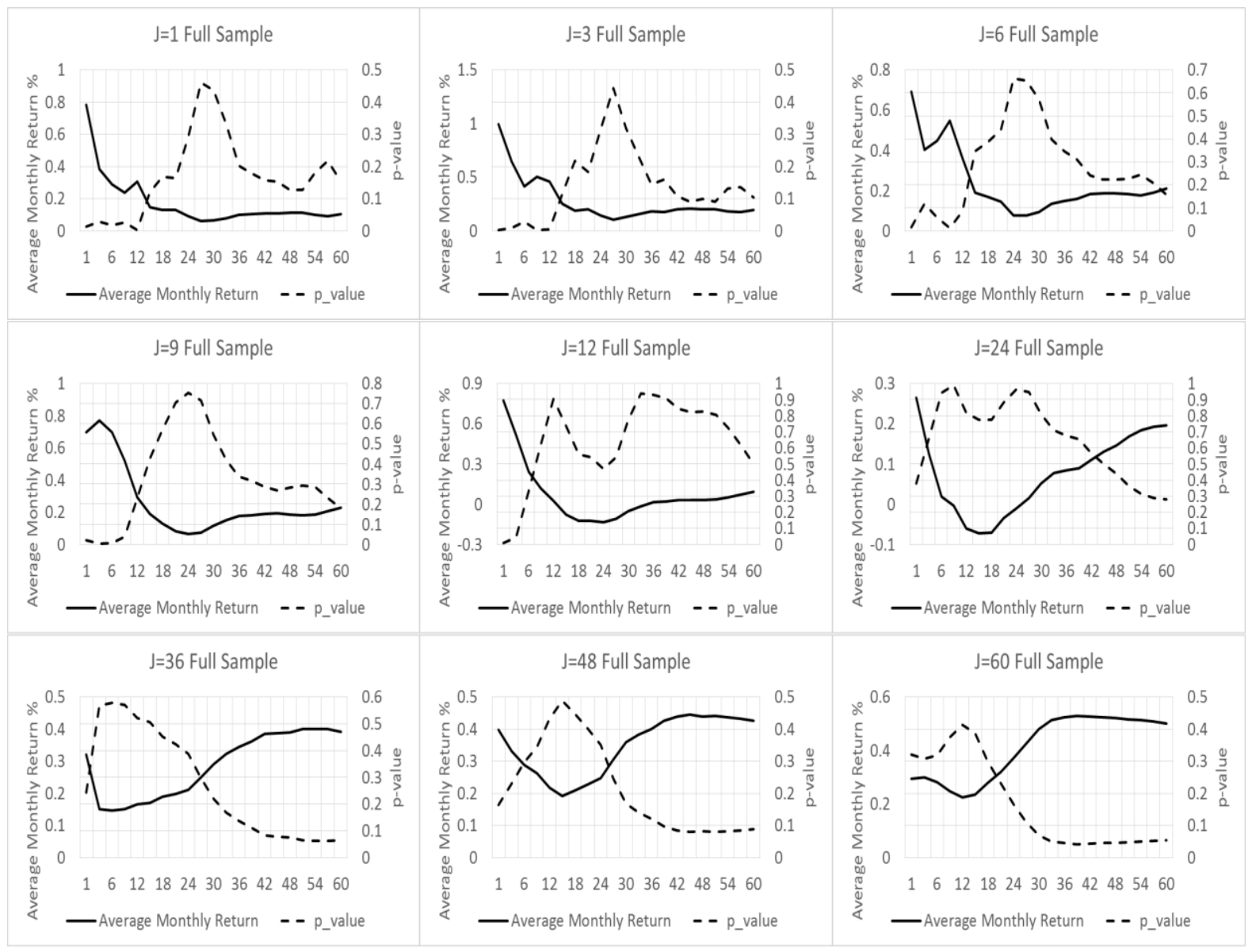

Panel D: The 52-week high momentum strategy of George and Hwang (2004) 


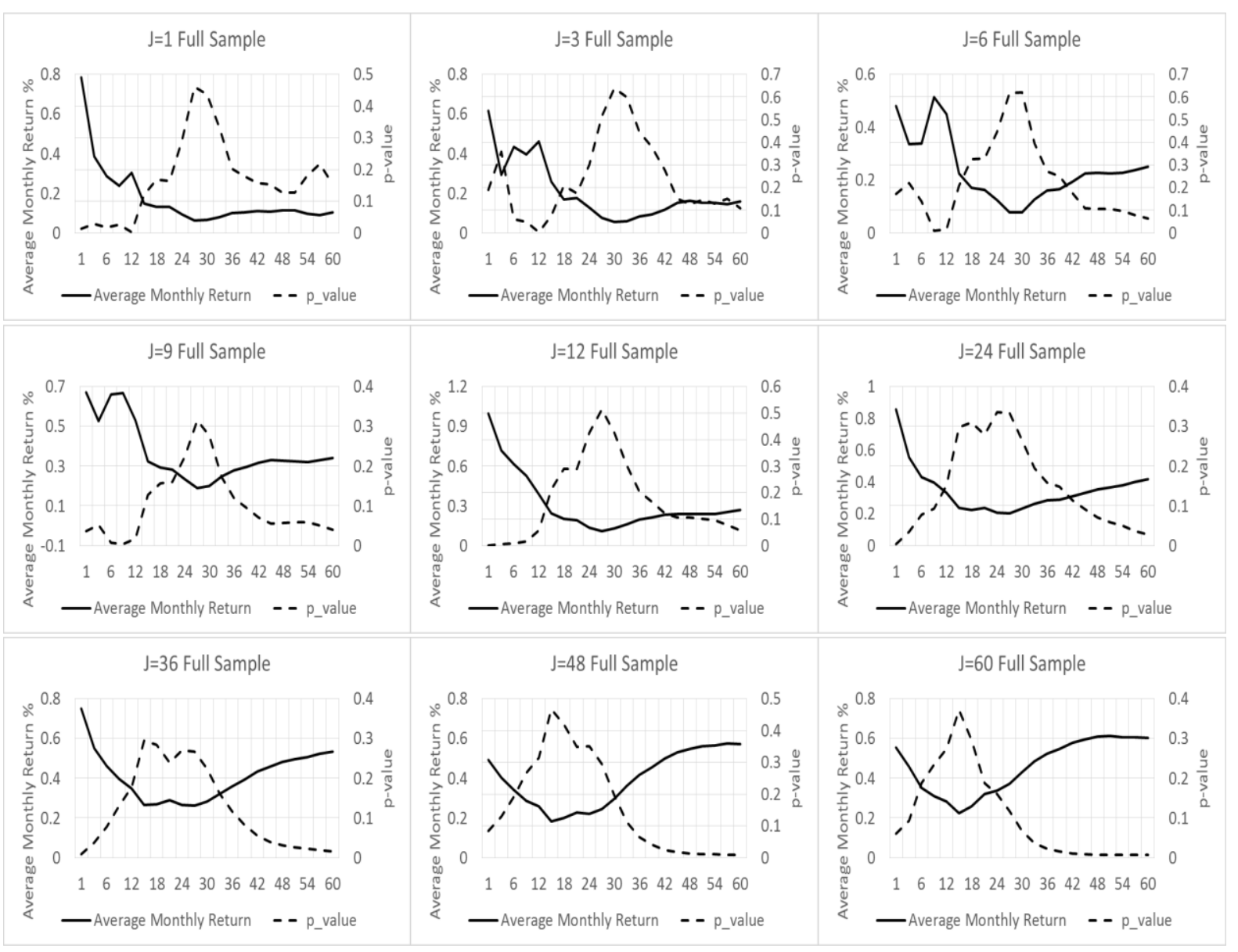

Figure 2. Performances of trading strategies across formation-holding windows and samples 
Notes. This Figure box plots the performances of the inverse of GGR pairs trading strategies (CC and FI) and momentum trading strategies (GH and JT). When the trading signals appear, the inverse of GGR strategies buying (selling) the commodity future with higher (lower) normalized price for each pair. Each trading strategy has 189 formation-holding $(9 \times 21)$ combinations. See Figure A1 for understanding the box plot.
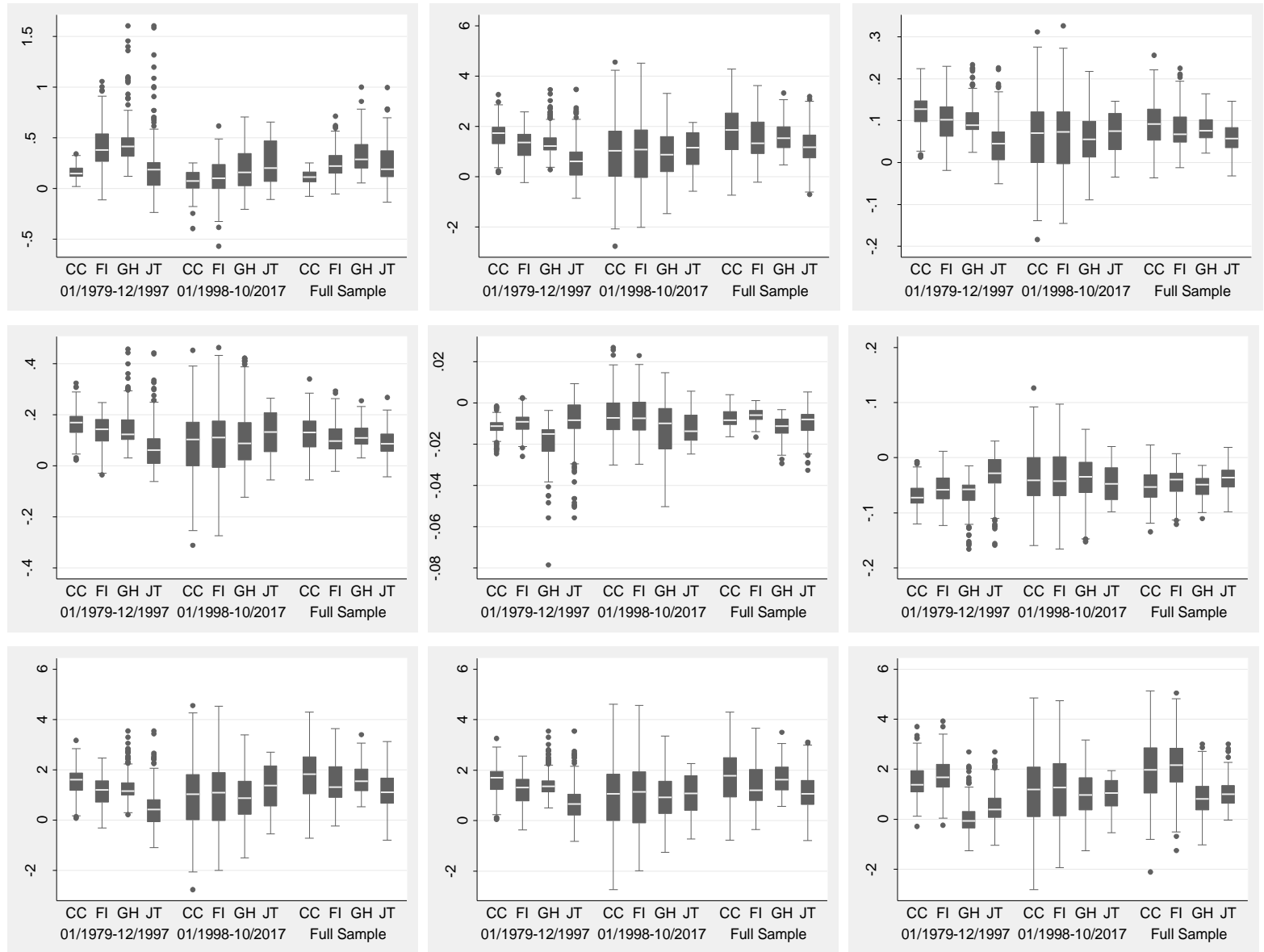

\section{Appendix}

Figure A1. Box plot

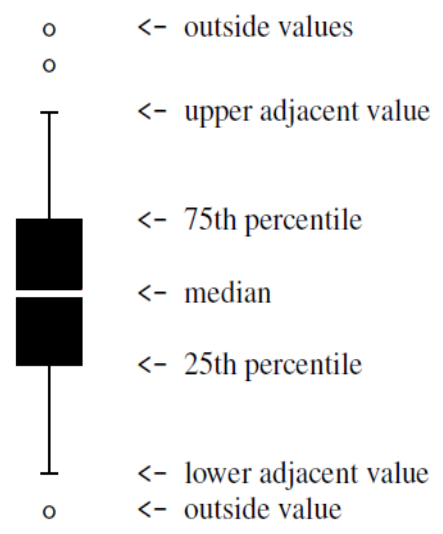

\section{References}


Ang, A. and Timmermann, A. (2012) 'Regime changes and financial markets', Annual Review of Financial Economics, 4(1), pp. 313-337.

Back, J., Prokopczuk, M. and Rudolf, M. (2013) 'Seasonality and the valuation of commodity options', Journal of Banking and Finance, 37(2), pp. 273-290.

Bai, J. and Perron, P. (1998) 'Estimating and testing linear models with multiple structural changes', Econometrica, 66(1), pp. 47-78.

Barberis, N., Shleifer, A. and Vishny, R. (1998) 'A model of investor sentiment', Journal of Financial Economics, 49(3), pp. 307-343.

Barroso, P. and Santa-Clara, P. (2015) 'Momentum has its moments', Journal of Financial Economics, 116(1), pp. 111-120.

Basu, D. and Miffre, J. (2013) 'Capturing the risk premium of commodity futures: The role of hedging pressure', Journal of Banking and Finance, 37(7), pp. 2652-2664.

Baur, D.G. and Lucey, B.M. (2010) 'Is gold a hedge or a safe haven? An analysis of stocks, bonds and gold', Financial Review, 45(2), pp. 217-229.

Bhootra, A. and Hur, J. (2013) 'The timing of 52-week high price and momentum', Journal of Banking and Finance, 37(10), pp. 3773-3782.

Bianchi, R.J., Drew, M.E. and Fan, J.H. (2015) 'Combining momentum with reversal in commodity futures', Journal of Banking and Finance, 59(Supplement C), pp. 423-444.

Bianchi, R.J., Drew, M.E. and Fan, J.H. (2016) 'Commodities momentum: A behavioral perspective', Journal of Banking and Finance, 72(Supplement C), pp. 133-150.

Bianchi, R.J., Drew, M.E. and Zhu, R. (2009) 'Pairs trading profits in commodity futures markets', Asian Finance Association International Conference 2009.

Bowen, D.A. and Hutchinson, M.C. (2016) 'Pairs trading in the UK equity market: Risk and return', European Journal of Finance, 22(14), pp. 1363-1387.

Broussard, J.P. and Vaihekoski, M. (2012) 'Profitability of pairs trading strategy in an illiquid market with multiple share classes', Journal of International Financial Markets, Institutions and Money, 22(5), pp. 1188-1201.

Chen, Q., Hua, X. and Jiang, Y. (2018) 'Contrarian strategy and herding behaviour in the Chinese stock market', European Journal of Finance, 24(16), pp. 1552-1568.

Chiang, T.C. and Zheng, D. (2010) 'An empirical analysis of herd behavior in global stock markets', Journal of Banking and Finance, 34(8), pp. 1911-1921.

Connolly, R. and Stivers, C. (2003) 'Momentum and reversals in equity-index returns during periods of abnormal turnover and return dispersion', Journal of Finance, 58(4), pp. 1521-1556.

Conrad, J. and Kaul, G. (1998) 'An anatomy of trading strategies', Review of Financial Studies, 11(3), pp. 489-519.

Cox, D.R. and Peterson, D.R. (1994) 'Stock returns following large one-day declines: Evidence on short-term reversals and longer-term performance', Journal of Finance, 49(1), pp. 255-267. 
Daniel, K. and Moskowitz, T.J. (2016) 'Momentum crashes', Journal of Financial Economics, 122(2), pp. 221-247.

De Bondt, F.M.W. and Thaler, R. (1985) 'Does the stock market overreact?', Journal of Finance, 40(3), pp. 793-805.

de Groot, W., Karstanje, D. and Zhou, W. (2014) 'Exploiting commodity momentum along the futures curves', Journal of Banking and Finance, 48(Supplement C), pp. 79-93.

Dempster, M.A.H., Medova, E. and Tang, K. (2008) 'Long term spread option valuation and hedging', Journal of Banking and Finance, 32(12), pp. 2530-2540.

Do, B. and Faff, R. (2010) 'Does simple pairs trading still work?', Financial Analysts Journal, 66(4), pp. 83-95.

Do, B. and Faff, R. (2012) 'Are pairs trading profits robust to trading costs', Journal of Financial Research, 35(2), pp. 261-287.

Economou, F., Kostakis, A. and Philippas, N. (2011) 'Cross-country effects in herding behaviour: Evidence from four south European markets', Journal of International Financial Markets, Institutions and Money, 21(3), pp. 443-460.

Erb, C.B. and Harvey, C.R. (2006) 'The strategic and tactical value of commodity futures', Financial Analysts Journal, 62(2), pp. 69-97.

Fama, E.F. and French, K.R. (1987) 'Commodity futures prices: Some evidence on forecast power, premiums, and the Theory of Storage', Journal of Business, 60(1), pp. 55-73.

Fama, E.F. and French, K.R. (1996) 'Multifactor explanations of asset pricing anomalies', Journal of Finance, 51(1), pp. 55-84.

Fuertes, A.-M., Miffre, J. and Fernandez-Perez, A. (2015) 'Commodity strategies based on momentum, term structure, and idiosyncratic volatility', Journal of Futures Markets, 35(3), pp. 274-297.

Fuertes, A.-M., Miffre, J. and Rallis, G. (2010) 'Tactical allocation in commodity futures markets: Combining momentum and term structure signals', Journal of Banking and Finance, 34(10), pp. 25302548.

Gatev, E., Goetzmann, W.N. and Rouwenhorst, K.G. (2006) 'Pairs trading: Performance of a relativevalue arbitrage rule', Review of Financial Studies, 19(3), pp. 797-827.

George, T.J. and Hwang, C.-Y. (2004) 'The 52-week high and momentum investing', Journal of Finance, 59(5), pp. 2145-2176.

Gibbons, M.R., Ross, S.A. and Shanken, J. (1989) 'A test of the efficiency of a given portfolio', Econometrica, 57(5), pp. 1121-1152.

Gonzalo, J. and Pitarakis, J.-Y. (2002) 'Estimation and model selection based inference in single and multiple threshold models', Journal of Econometrics, 110(2), pp. 319-352.

Goodwin, T.H. (1998) 'The Information Ratio', Financial Analysts Journal, 54(4), pp. 34-43.

Hamilton, J.D. (1989) 'A new approach to the economic analysis of nonstationary time series and the business cycle', Econometrica, 57(2), pp. 357-384.

Hansen, B.E. (2000) 'Sample splitting and threshold estimation', Econometrica, 68(3), pp. 575-603. 
Hansen, B.E. (2011) 'Threshold autoregression in economics', Statistics and Its Interface, 4, pp. 123127.

Hong, H., Lim, T. and Stein, J.C. (2000) 'Bad news travels slowly: Size, analyst coverage, and the profitability of momentum strategies', Journal of Finance, 55(1), pp. 265-295.

Hong, H. and Stein, J.C. (1999) 'A unified theory of underreaction, momentum trading, and overreaction in asset markets', Journal of Finance, 54(6), pp. 2143-2184.

Jacobs, H. and Weber, M. (2015) 'On the determinants of pairs trading profitability', Journal of Financial Markets, 23, pp. 75-97.

Jegadeesh, N. and Titman, S. (1993) 'Returns to buying winners and selling losers: Implications for stock market efficiency', Journal of Finance, 48(1), pp. 65-91.

Jegadeesh, N. and Titman, S. (2001) 'Profitability of momentum strategies: An evaluation of alternative explanations', Journal of Finance, 56(2), pp. 699-720.

Kim, A.Y., Tse, Y. and Wald, J.K. (2016) 'Time series momentum and volatility scaling', Journal of Financial Markets, 30, pp. 103-124.

Korajczyk, R.A. and Sadka, R. (2004) 'Are momentum profits robust to trading costs?', Journal of Finance, 59(3), pp. 1039-1082.

Krauss, C. (2017) 'Statistical arbitrage pairs trading strategies: Review and outlook', Journal of Economic Surveys, 31(2), pp. 513-545.

Lee, C.M.C. and Swaminathan, B. (2000) 'Price momentum and trading volume', Journal of Finance, 55(5), pp. 2017-2069.

Lesmond, D.A., Schill, M.J. and Zhou, C. (2004) 'The illusory nature of momentum profits', Journal of Financial Economics, 71(2), pp. 349-380.

Liu, B., Chang, L.-B. and Geman, H. (2017) 'Intraday pairs trading strategies on high frequency data: the case of oil companies', Quantitative Finance, 17(1), pp. 87-100.

Liu, M., Liu, Q. and Ma, T. (2011) 'The 52-week high momentum strategy in international stock markets', Journal of International Money and Finance, 30(1), pp. 180-204.

Locke, P.R. and Venkatesh, P.C. (1997) 'Futures market transaction costs', Journal of Futures Markets, 17(2), pp. 229-245.

Lubnau, T. and Todorova, N. (2015) 'Trading on mean-reversion in energy futures markets', Energy Economics, 51, pp. 312-319.

Marshall, B.R., Nguyen, N.H. and Visaltanachoti, N. (2012) 'Commodity liquidity measurement and transaction costs', Review of Financial Studies, 25(2), pp. 599-638.

Miffre, J. and Rallis, G. (2007) 'Momentum strategies in commodity futures markets', Journal of Banking and Finance, 31(6), pp. 1863-1886.

Moskowitz, T.J., Ooi, Y.H. and Pedersen, L.H. (2012) 'Time series momentum', Journal of Financial Economics, 104(2), pp. 228-250.

Narayan, P.K., Ahmed, H.A. and Narayan, S. (2015) 'Do momentum-based trading strategies work in the commodity futures markets?', Journal of Futures Markets, 35(9), pp. 868-891. 
Nelson, D.B. (1991) 'Conditional heteroskedasticity in asset returns: A new approach', Econometrica, 59(2), pp. 347-370.

Novy-Marx, R. (2012) 'Is momentum really momentum?', Journal of Financial Economics, 103(3), pp. 429-453.

Park, A. and Sabourian, H. (2011) 'Herding and contrarian behavior in financial markets', Econometrica, 79(4), pp. 973-1026.

Rad, H., Low, R.K.Y. and Faff, R. (2016) 'The profitability of pairs trading strategies: Distance, cointegration and copula methods', Quantitative Finance, 16(10), pp. 1541-1558.

Schmitt, N. and Westerhoff, F. (2017) 'Herding behaviour and volatility clustering in financial markets', Quantitative Finance, 17(8), pp. 1187-1203.

Shen, Q., Szakmary, A.C. and Sharma, S.C. (2007) 'An examination of momentum strategies in commodity futures markets', Journal of Futures Markets, 27(3), pp. 227-256.

Sun, Q. and Tong, W.H.S. (2010) 'Risk and the January effect', Journal of Banking and Finance, 34(5), pp. $965-974$.

Wang, C. and Yu, M. (2004) 'Trading activity and price reversals in futures markets', Journal of Banking and Finance, 28(6), pp. 1337-1361.

Zhang, H., Auer, B.R. and Vortelinos, D.I. (2018) 'Performance ranking (dis)similarities in commodity markets', Global Finance Journal, 35, pp. 115-137.

Zhang, H. and Urquhart, A. (2019) 'Pairs trading across Mainland China and Hong Kong stock markets', International Journal of Finance and Economics, 24(2), pp. 698-726. 